\title{
A probabilistic model-based soft sensor to monitor lactic acid bacteria fermentations
}

\author{
Spann, Robert; Roca, Christophe ; Kold, David ; Eliasson Lantz, Anna; Gernaey, Krist V.; Sin, Gürkan
}

Published in:

Biochemical Engineering Journal

Link to article, DOI:

10.1016/j.bej.2018.03.016

Publication date:

2018

Document Version

Peer reviewed version

Link back to DTU Orbit

Citation (APA):

Spann, R., Roca, C., Kold, D., Eliasson Lantz, A., Gernaey, K. V., \& Sin, G. (2018). A probabilistic model-based soft sensor to monitor lactic acid bacteria fermentations. Biochemical Engineering Journal, 135, 49-60. https://doi.org/10.1016/j.bej.2018.03.016

\section{General rights}

Copyright and moral rights for the publications made accessible in the public portal are retained by the authors and/or other copyright owners and it is a condition of accessing publications that users recognise and abide by the legal requirements associated with these rights.

- Users may download and print one copy of any publication from the public portal for the purpose of private study or research.

- You may not further distribute the material or use it for any profit-making activity or commercial gain

- You may freely distribute the URL identifying the publication in the public portal 


\section{Accepted Manuscript}

Title: A probabilistic model-based soft sensor to monitor lactic acid bacteria fermentations

Authors: Robert Spann, Christophe Roca, David Kold, Anna Eliasson Lantz, Krist V. Gernaey, Gürkan Sin

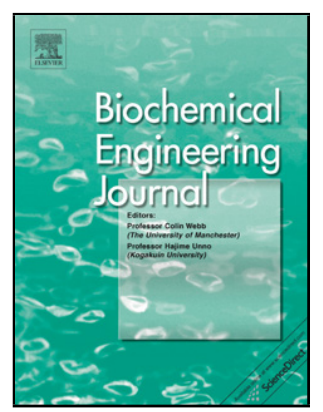

PII: S1369-703X(18)30099-8

DOI: https://doi.org/10.1016/j.bej.2018.03.016

Reference: BEJ 6919

To appear in: Biochemical Engineering Journal

Received date: 21-11-2017

Revised date: 20-2-2018

Accepted date: 16-3-2018

Please cite this article as: Spann R, Roca C, Kold D, Lantz AE, Gernaey KV, Sin G, A probabilistic model-based soft sensor to monitor lactic acid bacteria fermentations, Biochemical Engineering Journal (2010), https://doi.org/10.1016/j.bej.2018.03.016

This is a PDF file of an unedited manuscript that has been accepted for publication. As a service to our customers we are providing this early version of the manuscript. The manuscript will undergo copyediting, typesetting, and review of the resulting proof before it is published in its final form. Please note that during the production process errors may be discovered which could affect the content, and all legal disclaimers that apply to the journal pertain. 


\section{A probabilistic model-based soft sensor to monitor lactic acid bacteria fermentations}

Robert Spann ${ }^{\mathrm{a}}$, Christophe Roca ${ }^{\mathrm{b}}$, David Kold ${ }^{\mathrm{b}}$, Anna Eliasson Lantz ${ }^{\mathrm{c}}$, Krist V. Gernaey ${ }^{\mathrm{a}}$, Gürkan $\operatorname{Sin}^{\mathrm{a}^{*}}$

${ }^{a}$ Process and Systems Engineering Center (PROSYS), Department of Chemical and Biochemical Engineering, Technical University of Denmark, Soeltofts Plads Building 229, 2800 Kgs. Lyngby, Denmark

${ }^{\mathrm{b}}$ Chr. Hansen A/S, Boege Allé 10-12, 2970 Hoersholm, Denmark

${ }^{c}$ PILOT PLANT, Department of Chemical and Biochemical Engineering, Technical University of Denmark, Soeltofts Plads Building 229, 2800 Kgs. Lyngby, Denmark

\section{* Corresponding author:}

Gürkan Sin

Technical University of Denmark

Søltofts Plads Building 229

2800 Kgs. Lyngby, Denmark

Tel: +4545252806

E-mail address: gsi@kt.dtu.dk

Declaration of interest: none 


\title{
Graphical abstarct
}

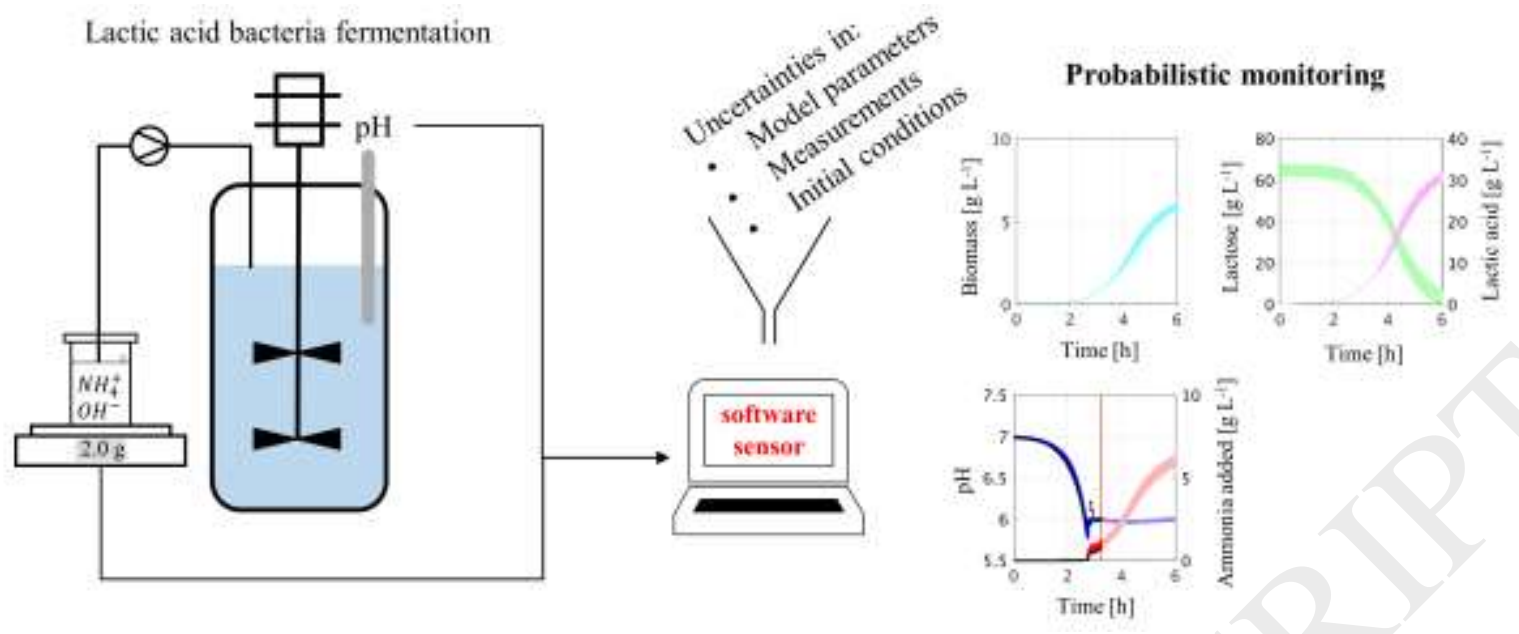

\section{Highlights}

- A model-based soft sensor for the monitoring of lactic acid bacteria is proposed

- Predictions based on limited available on-line measurements: base addition and $\mathrm{pH}$

- Coupling of a biokinetic model and a mixed weak acid/base model

- Uncertainties are quantified and accounted for using Monte Carlo simulations

- Probabilistic prediction for on-line risk-based monitoring and control

\begin{abstract}
A probabilistic soft sensor based on a mechanistic model was designed to monitor

S. thermophilus fermentations, and validated with experimental lab-scale data. It considered uncertainties in the initial conditions, on-line measurements, and model parameters by performing Monte Carlo simulations within the monitoring system. It predicted, therefore, the probability distributions of the unmeasured states, such as biomass, lactose, and lactic acid concentrations. To this end, a mechanistic model was developed first, and a statistical parameter estimation was performed in order to assess parameter sensitivities and
\end{abstract}


uncertainties. The model coupled a biokinetic and a mixed weak acid/base model to predict biological variables and chemical variables like the $\mathrm{pH}$, respectively. In the soft sensor, the limited available on-line measurements, namely the quantity of added ammonia and $\mathrm{pH}$, were used to update the model parameters that were then used as input to the mechanistic model. The soft sensor predicted both the current state variables, as well as the future course of the fermentation, e.g. with a relative mean error of the biomass concentration of $8 \%$. This successful implementation of a process analytical technology monitoring system opens up further opportunities, including for on-line risk-based monitoring and control applications.

Keywords: lactic acid bacteria (LAB) fermentation; modelling; soft sensor for monitoring; uncertainty analysis; process risk assessment; process analytical technology (PAT) 


\section{Introduction}

Lactic acid bacteria (LAB) are used as starter cultures in the dairy industry, to produce probiotics, lactic acid, and exopolysaccharides [1,2]. Streptococcus thermophilus strains are aerotolerant, homofermentative LAB and traditionally used as fermentation starter cultures for yogurt and cheese production. The bacteria are produced in batch and fed-batch fermentations, and real-time monitoring of the process is needed in order to understand and optimize the production process. However, robust in-line sensors for key process variables, like biomass, substrate, and lactic acid concentrations, are not available in the required concentration range due to the high complexity of the fermentation system [3]. This makes the real-time quantification of key process variables challenging. The process analytical technology (PAT) guidance from the FDA [4] requested already the development of real-time monitoring and control tools. The tools are meant to enhance the on-line monitoring and control capabilities. Hence, process conditions could be adjusted in real time to assure quality requirements, instead of relying solely on the end product quality control. Although the guidelines were originally intended for the (bio-) pharmaceutical industry, they have also been applied in other life science industries like the food industry.

Soft sensors, which utilize the on-line available measurements, are applied to predict the unknown state variables and monitor the fermentation process in real time [5-7]. There are, generally spoken, data-based and model-based soft sensors, whereas also other approaches exist. Chemometric methods like principal component analysis (PCA) may be applied in data-based soft sensors [8]. Model-based soft sensors can for example be based on mechanistic understanding using first principles models (e.g. the mass balance), or empirical models, when the details of the process are not understood sufficiently. The development of first principles models is based on a fundamental process understanding and mechanistic 
models may be implemented. Even though the development of mechanistic models might be time consuming, we prefer to use mechanistic models since they have many advantages over black-box models, e.g. that they can be reused and applied to multiple processes by updating the model parameters [7].

Soft sensors rely typically on available on-line and at-line measurements, such as $\mathrm{pH}$, conductivity, dissolved oxygen, heat generation, acid/base addition for $\mathrm{pH}$ control, and exhaust gas analysis. Different spectroscopic measurements, e.g. near-infrared [9], multiwavelength [10], and Raman [11] spectroscopy have also been used beside other methods in data-based soft sensor applications in fermentations. Mears et al. [12] applied a model-based soft sensor for on-line monitoring to a filamentous fungal fermentation at pilot scale using exhaust gas measurements and ammonia addition, and predicted various state variables (biomass, product, dissolved oxygen, $\mathrm{k}_{\mathrm{L}} \mathrm{a}$ among others). However, especially aerotolerant, homofermentative LAB fermentations lack various on- and at-line measurements, such as exhaust gas measurements, and rely solely on conductivity, $\mathrm{pH}$, and base addition measurements.

When developing and applying mechanistic models for bioprocesses it is good modelling practice for PAT applications to analyze the reliability of the model $[13,14]$. Unfortunately, models describing LAB fermentations rarely provide reported results of identifiability, sensitivity, or uncertainty analysis, e.g. confidence intervals of the estimated parameters. If a model with unreliable parameters is applied as a soft sensor, predictions will be doubtful and the results could lead to questionable interpretations. Furthermore, a deterministic model implementation may lead to a good fit, but does not take the imperfect knowledge, i.e. uncertainties of model parameters and measurements into account. Several studies 
implemented soft sensors to monitor LAB [15-18], but they did not consider uncertainties in the model structure.

The aim of this study was therefore to design and evaluate a probabilistic model-based soft sensor in order to monitor $S$. thermophilus fermentations. To this end, a mechanistic model was first developed and validated, and then used as soft sensor for monitoring at lab scale. A statistical parameter estimation was performed to analyze parameter uncertainties. The soft sensor comprised a data reconciliation module, a parameter update module and the dynamic model. The data reconciliation and parameter update module updated model parameters based on the available on-line measurements. One major challenge of this study was that only $\mathrm{pH}$ and ammonia addition measurements were available on-line, whereas e.g. exhaust gas measurements were not available. The dynamic model consisted of a biokinetic and a chemical model. The biokinetic model described substrate consumption, biomass growth, and lactic acid secretion while the chemical model comprised a mixed weak acid/base system with the purpose to predict the $\mathrm{pH}$. Monte Carlo simulations of the dynamic model were performed within the monitoring system to account for uncertainties in the lactose (substrate) concentration, ammonia addition rate, and model parameters. The output of the monitoring system was consequently a probability distribution of the state variables.

\section{Materials and Methods}

\subsection{Fermentation conditions}

Streptococcus thermophilus batch fermentations were performed in 2 L stirred tank bioreactors (Biostat ${ }^{\circledR} \mathrm{B}$, Sartorius AG, Germany) at $300 \mathrm{rpm}, 40{ }^{\circ} \mathrm{C}$, and with nitrogen headspace gassing. The $\mathrm{pH}$ was controlled by adding $24 \%$ ammonia solution. 10 batch fermentations were performed under different cultivation conditions (initial lactose concentration 20 or $65 \mathrm{~g} \mathrm{~L}^{-1}$, pH 5.5 - 7.0) and used for the parameter estimation, model 
validation, and implementation of the monitoring system (see Table 4 in the Results and Discussion section). The $\mathrm{pH}$ (EasyFerm Bio VP 225, Hamilton Robotics, Reno, NV) and ammonia addition (balance value) were measured on-line. The fermentation medium contained 20 or $65 \mathrm{~g} \mathrm{~L}^{-1}$ lactose, $10 \mathrm{~g} \mathrm{~L}^{-1}$ casein hydrolysate, $12 \mathrm{~g} \mathrm{~L}^{-1}$ yeast extract, $11.5 \mathrm{mM}$ $\mathrm{K}_{2} \mathrm{HPO}_{4}, 36.6 \mathrm{mM}$ sodium acetate, $8.2 \mathrm{mM}$ trisodium citrate, $0.8 \mathrm{mM} \mathrm{MgSO}_{4}$, and $0.3 \mathrm{mM}$ $\mathrm{MnSO}_{4}$.

\subsection{Off-line analysis}

Sugars and organic acids were quantified from filtered samples (filter pore size: $0.2 \mu \mathrm{m}$ ) in an HPLC system (Dionex UltiMate 3000, Thermo Fisher Scientific, Waltham, MA). It was equipped with an Aminex ${ }^{\circledR}$ HPX-87H column (Bio-Rad Laboratories, Hercules, CA) and a refractive index detector (ERC RefractoMax 520), and run with $5 \mathrm{mM} \mathrm{H}_{2} \mathrm{SO}_{4}$ at a flow rate of $0.6 \mathrm{~mL} \mathrm{~min}^{-1}$ at $50{ }^{\circ} \mathrm{C}$ according to suppliers instructions. Samples were diluted 1:4 with $5 \mathrm{mM} \mathrm{H}_{2} \mathrm{SO}_{4}$ prior to analysis. Dry cell weight was quantified with replicates of $2 \mathrm{~mL}$ cell broth, which were taken in sampling tubes, centrifuged, washed with $0.9 \%(w / v) ~ N a C l$ solution, dried at $70{ }^{\circ} \mathrm{C}$ for $24 \mathrm{~h}$, and weighted. Ammonia and phosphate were quantified with the cuvette tests LCK302, LCK303, and LCK350 (Hach ${ }^{\circledR}$, Manchester, Great Britain).

\subsection{Biological model}

The dynamic biokinetic model described the evolution of the state variables such as biomass, lactose, and lactic acid of the S. thermophilus fermentation. The model was based on the global stoichiometric process equation [19] (Eq. 1 - 2). The biomass growth rate was modelled as a function depending on the lag-time ( $\left.f_{\text {lag }}\right)$, lactose inhibition and limitation ( $\left.f_{\mathrm{S}}\right)$ [20], lactate inhibition $\left(\mathrm{f}_{\mathrm{P}}\right)$ [21], and the $\mathrm{pH}\left(\mathrm{f}_{\mathrm{pH}}\right)$ [22] (Eq. $\left.3-4\right)$. It was assumed that only the dissociated form of lactic acid was growth inhibiting under the investigated $\mathrm{pH}$ conditions according to the studies of Schepers et al. [22] and Amrane and Prigent [23]. A biomass composition of $\mathrm{CH}_{1.95} \mathrm{O}_{0.63} \mathrm{~N}_{0.22} \mathrm{P}_{0.02}$ [24] was assumed in the present study. 


$$
\begin{gathered}
\text { Lactose }+ \text { Ammonia }+ \text { Phosphoric acid } \rightarrow \text { Biomass }+ \text { Lactic acid }+ \text { Galactose } \\
\mathrm{q}_{\mathrm{S}} \cdot \mathrm{CH}_{2} \mathrm{O}+\mathrm{q}_{\mathrm{NH}} \cdot N H_{3}+\mathrm{q}_{\mathrm{Ph}} \cdot H_{3} \mathrm{PO}_{4} \rightarrow \mathrm{q}_{\mathrm{X}} \cdot \mathrm{CH}_{\mathrm{a}} \mathrm{O}_{\mathrm{b}} \mathrm{N}_{\mathrm{c}} \mathrm{P}_{\mathrm{d}}+\mathrm{q}_{\mathrm{P}} \cdot \mathrm{CH}_{2} \mathrm{O}+\mathrm{q}_{\mathrm{Gal}} \cdot \mathrm{CH}_{2} \mathrm{O} \\
\frac{d C_{X}}{d t}=\mu_{\max } \cdot f_{\text {lag }} \cdot f_{S} \cdot f_{P} \cdot f_{p H} \cdot C_{X} \\
\frac{d C_{X}}{d t}=\mu_{\max } \cdot\left(1-e^{\left.-\frac{t}{t_{l a g}}\right)} \cdot \frac{C_{S}}{C_{S}+K_{S}+\frac{C_{S}^{2}}{K_{I}}} \cdot \frac{1}{1+e^{K_{P, L a}\left(C_{L A}-K_{L a 1}\right)} \cdot e^{-\left(\frac{\left(p H_{o p t}-p H\right)^{2}}{\sigma_{p H}^{2}}\right)} \cdot C_{X}}\right.
\end{gathered}
$$

Where $\mathrm{K}_{\mathrm{La} 1}$ was dependent on the $\mathrm{pH}$ :

$$
K_{L a 1}=K_{L a} \cdot \frac{1}{1+e^{K_{P, p H 1} *\left(p H-K_{P, p H 2}\right)}}
$$

An amended Luedeking and Piret equation [25] that takes only the growth dependent lactic acid synthesis into account was used [26]:

$$
\frac{d C_{P}}{d t}=\alpha \cdot \frac{d C_{X}}{d t}
$$

The lactose consumption is the sum of the biomass growth and the lactic acid synthesis rate considering the secretion of galactose ( $\left.\mathrm{Y}_{\mathrm{gal}}\right)$ since the studied strain metabolizes only glucose and secretes galactose under the present cultivation conditions:

$$
\frac{d C_{S}}{d t}=-\left(1+Y_{g a l}\right) \cdot\left(\frac{d C_{X}}{d t}+\frac{d C_{P}}{d t}\right)
$$

A P-controller with a controller gain $\left(\mathrm{K}_{\mathrm{P}}\right)$ of $10 \mathrm{~mol}$ was applied to maintain the $\mathrm{pH}$ at the set point value by adding ammonia solution:

$$
\mathrm{NH}_{4} \mathrm{OH}_{\text {add }}=\mathrm{K}_{\mathrm{P}} \cdot\left(\mathrm{pH} \mathrm{H}_{\text {set }}-\mathrm{pH}\right)
$$

The model was implemented and solved in MATLAB ${ }^{\circledR}$ (The MathWorks ${ }^{\circledR}$, Natick, MA) using the solver ode15s. ode15s was chosen because the model contains slow (e.g. biomass growth) and fast time constants (mixed weak acid/base model, see below) resulting in a stiff system of differential equations. 


\subsection{Mixed weak acid/base model}

The purpose of the mixed weak acid/base model was to predict the $\mathrm{pH}$ during the fermentation. It comprised the dissociation reactions of the charged compounds in the fermentation broth as described in Musvoto et al. [27] (Table 1). The dissociation reactions of ammonia, phosphoric acid, lactic acid, carbonic acid, water, and an unspecified compound Z were considered. $\mathrm{Z}$ accounted for the unknown compounds in the fermentation broth, such as amino acids. The $\mathrm{pK}_{\mathrm{a}}$ values were derived from Dawson [28] and Loewenthal et al. [29] (Table 2). The activity coefficients were calculated by a modification of the Debye-Hückel theory from Davies [30]:

$$
\log \left(f_{i}\right)=-1.825 \cdot 10^{6} \cdot(78.3 \cdot T)^{-1.5} \cdot z_{i}^{2} \cdot\left(\frac{\sqrt{I}}{1+\sqrt{I}}-0.3 \cdot I\right)
$$

With the ionic strength (I):

$$
I=\frac{1}{2} \sum_{i} z_{i}^{2} C_{i}
$$

The implemented stoichiometric matrix may be found in the Supplementary Material.

\subsection{Parameter estimation}

The parameter estimation was performed to fit the experimental lactose, biomass, and lactic acid concentration measurements using the maximum likelihood estimation method from Seber and Wild [31]. The model was fitted to five fermentations, which were controlled at different constant $\mathrm{pH}(1 \mathrm{x} \mathrm{pH} 5.5,2 \mathrm{x} \mathrm{pH} 6.0,1 \mathrm{x} \mathrm{pH} \mathrm{6.5,} \mathrm{and} \mathrm{1x} \mathrm{pH} \mathrm{7.0)} \mathrm{and} \mathrm{were} \mathrm{performed}$ with an initial lactose concentration of $65 \mathrm{~g} \mathrm{~L}^{-1}$. For the parameter estimation, the $\mathrm{pH}$ was held constant at the set point in the simulation, and the mixed weak acid/base model was not considered in order to obtain parameter estimates that were independent of the mixed weak/acid base system. The parameter estimation followed the methodology from Sin and Gernaey [32] as described in Spann et al. [33]. Initial parameter estimates were taken from literature [20-22] (Supplementary Table S1). Sensitivity and identifiability analysis were 
conducted to find an identifiable parameter subset for regression [32]. Once the regression was completed, the confidence intervals of the estimated parameters were derived from a linear approximation method using the Jacobian matrix of the parameter estimation [34]. The parameter estimation was conducted in MATLAB with the nonlinear least-squares solver 1sqnonlin. In the objective function, the weighted error of the model predictions was calculated for the three concentrations lactose, biomass, and lactic acid at all measured time points i (Eq. 11). The residuals vector then contained the weighted error vectors of the three states j.

$$
\text { Error }_{i}=\left|\frac{\hat{y}_{i}-y_{\text {meas }, i}}{w_{j}}\right|
$$

where $\mathrm{w}_{\mathrm{j}}$ is the maximum value of each specific component, here $65 \mathrm{~g} \mathrm{~L}^{-1}$ for lactose, $30 \mathrm{~g} \mathrm{~L}^{-1}$ for lactic acid, and $6 \mathrm{~g} \mathrm{~L}^{-1}$ for biomass. For model simplification purposes, the lagtime parameter, $\mathrm{t}_{\mathrm{lag}}$, was described as a $\mathrm{pH}$ dependent distribution, in order to account for the different lag-times observed for fermentations having a different $\mathrm{pH}$ set point (Eq. 12). This approach simplifies the model complexity significantly and requires the estimation of only 2 parameters, instead of 5 parameters that would have been needed, if $t_{\text {lag }}$ was fitted for each fermentation separately.

$$
t_{\text {lag }}=2 / e^{\frac{\left(p H_{\text {opt_lag }}-p H\right)^{2}}{\sigma_{\text {lag }}^{2}}}
$$

The uncertainty of the estimated parameters was quantified with the relative error (RE) between the standard deviation of the parameter estimate with respect to the estimated mean value:

$$
R E_{i}=\frac{\sigma_{\widehat{\theta}_{i}}}{\hat{\theta}_{i}}
$$

\subsection{Initial conditions}

The initial conditions for the dynamic model are given in Table 2. 


\subsection{Assessment of the model fit}

The goodness of fit for the model prediction in the model validation procedure and on-line monitoring application was assessed with the root mean sum of squared errors (RMSSE):

$$
R M S S E=\sqrt{\frac{1}{n} \sum_{i}^{n}\left(y_{\text {meas }, i}-\hat{y}_{i}\right)^{2}}
$$

\section{Framework for the soft sensor}

\subsection{Design of the probabilistic model-based soft sensor}

The objective of the probabilistic model-based soft sensor is to monitor the $S$. thermophilus fermentation. It predicts the probabilistic distribution of the states, such as biomass, lactose, lactic acid, and $\mathrm{pH}$, in real time based on the on-line available ammonia addition and the $\mathrm{pH}$ measurements. The soft sensor consists of a data reconciliation module, a parameter update module, and a dynamic process model (Fig. 1). The model parameters $\mu_{\max }$ and $\mathrm{t}_{\text {lag }}$ are updated every 5 minutes based on the latest on-line measurements, and the soft sensor predicts both the current value and the future course of the state variables. The current states are saved as initial conditions for the next interval. Monte Carlo simulations of the dynamic model are performed every interval using samples from the input uncertainty domain. To this end, the Latin hypercube sampling technique was used to generate 100 random samples from the input uncertainty domain in which we included uncertainties in the initial conditions, model parameters, and ammonia addition (Table 2). The outcome from the Monte Carlo simulations was a probability distribution of the state variables.

\subsubsection{Data reconciliation method}

The data reconciliation module is based on elemental and bio-energetic conservation principles such as the charge balance (Eq. 15) and the lactic acid production rate expression (Eq. 16). It uses the amount of added ammonia, where one measurement value is available every minute, to update the volumetric biomass growth and lactic acid production rate. The 
ammonia addition data points of each interval are fitted with a smoothing spline line and the average ammonia addition of the interval, $\mathrm{q}_{\mathrm{NH} \text {,add, }}$ is estimated. Missing measurement points can also be handled due to the implementation of the fit. With the data reconciliation the growth rate $\left(\mathrm{q}_{\mathrm{x}}\right)$ is obtained and used as input for the parameter update module.

$$
\begin{gathered}
\mathrm{NH}_{4}^{+}+\mathrm{C}_{3} \mathrm{H}_{5} \mathrm{O}_{3}^{-}=q_{N H, \text { add }}+q_{P}=0 \\
q_{P}=\alpha \cdot q_{X}
\end{gathered}
$$

\subsubsection{Parameter update}

The updated $\mathrm{qx}_{\mathrm{X}}$ is used to update $\mu_{\max }$ in every interval. $\mu_{\max }$ is updated in an iterative procedure until the change of $\mu_{\max }$ is less than $5 \%$ compared to the previous iteration. In the first iteration $(\mathrm{k}=1) \mu_{\max }$ is calculated based on the updated $\mathrm{q}_{\mathrm{x}}$, the function values, and biomass concentration of the previous interval (Eq. 17). The subsequent iterations use the function values and biomass concentration based on the new $\mu_{\max }$ value. The function values and biomass concentration derive from an evaluation of the dynamic model.

$$
\mu_{\max , k}=\frac{q_{X, \text { updated }}}{f_{\text {lag }, k-1} \cdot f_{S, k-1} \cdot f_{P, k-1} \cdot f_{p H, k-1} \cdot X_{k-1}}
$$

It is not possible to use the updated rates ( $\mathrm{q}_{\mathrm{P}}$ and $\mathrm{q}_{\mathrm{X}}$ ) directly in the dynamic model, as they resemble only the conditions of the previous 5 minutes. However, inhibition and limitation effects, as well as $\mathrm{pH}$ variations, which will occur during a fermentation, influence the rates. It is therefore necessary to calculate the rates within the dynamic model according to Eq. 4 and Eq. 6 in order to predict the future course of the fermentation, as well.

The lag-time parameter $\mathrm{t}_{\mathrm{lag}}$ is updated based on the measured $\mathrm{pH}$ value as soon as the measured $\mathrm{pH}$ reaches the controlling value (here $\mathrm{pH}=6$ ). The continuous $\mathrm{pH}$ measurement is saved every minute. $\mathrm{t}_{\mathrm{lag}}$ is adjusted so that the modelled and measured $\mathrm{pH}$ reach the control value at the same time (Eq. 18). $\mathrm{t}_{\text {lag }}$ is updated in an iterative procedure until the change is less than $2 \%$ compared to the previous iteration. 


$$
t_{\text {lag }, k}=t_{\text {lag }, k-1}+\left(t_{p H=6, \text { measured }}-t_{p H=6, \text { predicted }}\right)
$$

Once $t_{\text {lag }}$ is updated, the model is run from the beginning, because $t_{\text {lag }}$ influences the whole prediction range. The current state is then saved as initial conditions for the next iteration. The updated parameters $\mu_{\max }$ and $t_{\text {lag }}$ are used as input for the dynamic model.

\subsubsection{Dynamic mechanistic process model}

The dynamic process model comprises the biological model and the mixed weak acid/base model as described in the Materials and Methods section.

\subsubsection{Monte Carlo simulations}

The Monte Carlo method includes three main steps namely (1) identification and definition of input uncertainties, (2) sampling and (3) Monte Carlo simulation. For step 1, uncertainties in the biological model parameters, initial lactose concentration, initial biomass concentration, and the ammonia addition are considered (Table 2). The uncertainties of the model parameters are represented by the covariance matrix (includes the standard deviation and correlation matrix), which is derived from the parameter estimation. Uncertainties in the initial lactose and biomass concentration, and the measured ammonia addition are considered to be normally distributed with $3 \sigma=10 \%$. The model parameters are assumed to be normally distributed as well because the measurement errors, on which the parameter estimation is founded, are assumed to be normally distributed. In order to account for the ammonia addition uncertainty, samples with a normal distribution, a mean value 1 , and $3 \sigma=0.1$ are generated and will be multiplied with the measured ammonia addition rate in the Monte Carlo simulations. Uncertainties in the parameters of the mixed weak acid/base system are not considered since $\mathrm{pH}$ predictions were not necessary for the online monitoring application, as $\mathrm{pH}$ was directly measured and used as input for the data reconciliation module. The identification of uncertain input sources and the definition of the uncertainty ranges depend on the system studied. In general, this should therefore be systematically evaluated for each 
studied system separately. In this study, uncertainties of $5 \%$ were expected based on an expert discussion and considering the available data. To be on the safe side, we considered $3 \sigma=10 \%$ for the uncertainties in the initial conditions and the ammonia measurement. For step 2, the Latin Hypercube Sampling (LHS) technique is used together with the Iman Conover rank correlation method to induce the correlation matrix in the input domain (see step 1) $[35,36]$. The sampling procedure features the following generic steps: First, LHS sampling for independent inputs is performed in the unit probability domain [ $\left[\begin{array}{ll}0 & 1\end{array}\right]$ for $\mathrm{N}$ sampling numbers ( $\mathrm{N}=100$ used in this study). Then, the correlation matrix is induced via the Iman Conover method [37] for the correlated parameters. Finally, the correlated parameter samples are inverted from the probability domain to real values considering the inverse cumulative distribution function for each input e.g. using the Matlab function icdf. In this study, we assumed both measurement errors as well as parameter estimation errors to be normally distributed hence we set the option "Probability distribution name" to "Normal" in the icdf function. In this step, the user can define any other distribution function deemed appropriate as well (e.g. uniform, gamma etc.).

In step 3, Monte Carlo simulations of the dynamic model are performed for each sample. The output of the Monte Carlo simulations consists of 100 model predictions, representing a probabilistic distribution of the predicted state variables.

\section{Results and Discussion}

\subsection{Parameter estimation}

A parameter estimation of the biological model was performed in order to assess the model reliability. Uncertainty and sensitivity analysis were conducted to find an identifiable parameter subset. It must hereby be considered that the estimated parameters depend among others on the nominal parameter values, the cultivation conditions, and the model structure 
[34]. The first parameter estimation, fitting all biokinetic model parameters, revealed identifiability issues (Supplementary Table $\mathrm{S} 2$ ). $\mathrm{K}_{\mathrm{P}, \mathrm{pH} 1}, \mathrm{~K}_{\mathrm{P}, \mathrm{pH} 2}, \mathrm{~K}_{\mathrm{S}}$, and $\mathrm{K}_{\mathrm{I}}$ could not be estimated and were therefore maintained at their initial values for the subsequent steps. The subsequent parameter estimation with the remaining 9 parameters revealed an identifiable parameter subset. The estimated parameter values were in the expected range and in the order of magnitude as known from previous studies (Table 3). It has to be noted that $\mu_{\max }=2.06 \mathrm{~h}^{-1}$ was higher than the actual biological value because it had to compensate for the functions in the growth rate expression. The relative errors of all parameters were lower than $10 \%$. In addition, all parameters had a significant effect on the model outputs (Supplementary Table S3). Some of the parameters met the criterion of a correlation coefficient smaller than 0.5 to be uniquely identifiable. However, this parameter subset should be considered as a whole due to the linear dependency between most of the parameters. The estimated value of one parameter is conditional on the value of another parameter. Therefore, the covariance matrix of the parameters should be used, e.g. when performing parameter sampling in Monte Carlo simulations, when performing model simulations, as done in this work.

The model showed an acceptable fit of the fermentation data (Fig. 2, Supplementary Fig. S1 - 4). To measure process performance, the focus was on the biomass concentration because the cells were the target fermentation product. The RMSSE for biomass was around $0.4 \mathrm{~g} \mathrm{~L}^{-1}$ for many of the fermentations, corresponding to a discrepancy of less than $10 \%$, giving evidence of a good fit (Table 4). A good model fit was achieved for the fermentations at $\mathrm{pH} 5.5,6.0$, and 6.5 but not at $\mathrm{pH}=7.0$, which had an error of $30 \%$. Furthermore, the secretion of galactose was underestimated in all fermentations. This could be attributed to an inconsistent carbon balance in the experimental fermentation data, where more carbon was produced than lactose consumed. The supplemented yeast extract, which was not taken into 
account in the model, does contain approximately $6 \mathrm{~g} \mathrm{~L}^{-1}$ carbon [19] when assuming the elemental composition of a $S$. cerevisiae cell for the yeast extract. Hence, amino acids that derived from the yeast extract and were taken up by the cells might have led to the inconsistency in the carbon balance. The parameter estimation aimed therefore not to fit the galactose concentration, but it was anyhow kept in case the model will be extended in future studies.

The evaluation of the $\mathrm{pH}$ function $\mathrm{f}_{\mathrm{pH}}$ showed a clear maximum at $\mathrm{pH}=6.4$ (Fig. 3A). Furthermore, growth was already reduced by $25 \%$ at $\mathrm{pH}=5.5$ and 7 . Similar trends of the influence of the $\mathrm{pH}$ on the growth of LAB were observed in other studies $[21,38,39]$. These studies found slightly different $\mathrm{pH}$ optimums in the range between 6 and 7 since different strains were studied. The growth inhibition by lactate was $\mathrm{pH}$ dependent, as well (Fig. 3B). $20 \mathrm{~g} \mathrm{~L}^{-1}$ lactate inhibited growth by $50 \%$ in the $\mathrm{pH}$ range from 5.5 to 6.5 , whereas at $\mathrm{pH}=7$ already $10 \mathrm{~g} \mathrm{~L}^{-1}$ lactate inhibited growth by $50 \%$. pH dependent inhibition of growth caused by lactate was also already observed for the lactic acid producing bacterium Enterococcus faecalis [40]. This underlines the necessity of the $\mathrm{pH}$ dependent lactate inhibition parameter $\mathrm{K}_{\mathrm{La1}}$ (Eq. 5).

\subsection{Model validation}

Following the statistical assessment of the quality of the parameter estimates above, the model was validated against two independent fermentation data sets, which were performed at $\mathrm{pH}=6.0$ and an initial lactose concentration of $20 \mathrm{~g} \mathrm{~L}^{-1}$ (Fig. 4, Supplementary Fig. S5). The model predicted the measured lactose, biomass, lactic acid, and galactose concentrations (Fig. 4 A-D). The lag-time parameter $t_{\text {lag }}$ was fitted for both fermentations because the lag time differs from batch to batch. The assessment of the validation model fit showed that the model gave an acceptable prediction accuracy with an RMSSE for biomass of $0.2 \mathrm{~g} \mathrm{~L}^{-1}$ 
(Table 4). The $\mathrm{pH}$ prediction was also very accurate with a discrepancy of less than $0.1 \mathrm{pH}$ units (Fig. $4 \mathrm{E}$ ). In the beginning of the fermentation, the $\mathrm{pH}$ dropped from 6.1 to 6.0 before the controller started to add ammonia solution. This drop was predicted to be faster than actually measured, which could be attributed to a slightly different buffer capacity of the medium in reality compared to the mixed weak acid/base model. However, a prediction accuracy within $\pm 0.1 \mathrm{pH}$ units was deemed sufficiently accurate for monitoring purposes, as $\mathrm{pH}$ measurement errors were expected to be in the same range. The only exception of an accurate $\mathrm{pH}$ fit was at the moment when the $\mathrm{pH}$ controller started: too much ammonia was added in the experiment so that the $\mathrm{pH}$ showed an overshoot. The $\mathrm{pH}$ prediction is closely dependent on the predictions of the ammonia addition and lactic acid concentration. The validity of the mixed weak acid/base model was therefore demonstrated by a correct prediction of the added ammonia solution (Fig. 4 F), as the $\mathrm{pH}$ is held constant by adding ammonia solution. Nevertheless, the validity of the applied Davis equation to calculate the activity coefficients (Eq. 9) for $I \leq 0.5 \mathrm{~mol} \mathrm{~L}^{-1}$ has to be noted, and could be improved in future studies in particular for fermentations with an ionic strength higher than $1 \mathrm{~mol} \mathrm{~L}^{-1}$. Overall, these results indicate the validity of the model, which encourages its further application for monitoring of a fermentation process as presented below.

\subsection{Application of the probabilistic model-based soft sensor}

The probabilistic model-based soft sensor was applied to the data sets of three historical fermentations, where the historical on-line data was used as it would be available on-line. Here, the initial $\mathrm{pH}$ was around 7 and the $\mathrm{pH}$ dropped to the control value 6 due to acid secretion as by-product during the LAB fermentation (Fig. 5, Supplementary Fig. S6 and S7, while the Supplementary Movies show the virtual on-line implementation of the soft sensor). The on-line data, namely $\mathrm{pH}$ and quantity of added ammonia were used as an input to update the monitoring system (Fig. 5 left column). The Monte Carlo propagation of the error for the 
biomass, lactose, and lactic acid concentration is then predicted by the monitoring system (Fig. 5 middle and right column). The predictions of the future states of the system are shown at different times, 2 h, 2 h 40 min, 3 h, 4 h, and 6 h (Fig. 5 rows). Since the $\mathrm{pH}$ was higher than the control value 6 , no ammonia solution was added within the first $2 \mathrm{~h}$ and $35 \mathrm{~min}$. Therefore, no data reconciliation and parameter update were conducted (Fig. 5, time $=2 \mathrm{~h}$ ), and Monte Carlo simulations were performed in the defined input uncertainty space (Table 2 and Supplementary Fig. S8) considering uncertainties in the biological model parameters and initial conditions. The monitoring system was running without updating the parameters until the ammonia addition started to control the $\mathrm{pH}$ (Fig. 5, at time $=2 \mathrm{~h} 40 \mathrm{~min}$ ). At this point, $t_{\text {lag }}$ was updated ensuring that the $\mathrm{pH}$ controller in the experiment and simulation started at the same time. It is clear that there is a lag-time variation from batch to batch, which has to be taken into account. On the one hand, a dependency on the $\mathrm{pH}$ measurement is introduced by this procedure. On the other hand, it is the only possibility - given the limited amount of online measurements - to align the modelled and measured ammonia addition, which is crucial for the monitoring system. Once $t_{\text {lag }}$ was updated, and the ammonia addition started, the data reconciliation and parameter update modules updated $\mu_{\max }$ every 5 minutes, as described in the Framework description. With time, more measurement information was available and the prediction accuracy of the state variables increased (Fig.5, time $=3 \mathrm{~h}-6 \mathrm{~h}$ ).

The RMSSE for biomass was $0.8 \mathrm{~g} \mathrm{~L}^{-1}$ when the fermentation started, and improved to $0.5 \mathrm{~g} \mathrm{~L}^{-1}$ at the end of the fermentation (both with a standard deviation of $0.1 \mathrm{~g} \mathrm{~L}^{-1}$ ) (Fig. 6). Mainly, the update of $\mathrm{t}_{\mathrm{lag}}$ after $2 \mathrm{~h}$ and 40 minutes of the fermentation improved the prediction accuracy. The reproducibility of the Monte Carlo simulations was validated as the RMSSE for biomass varied less than $0.5 \%$ in 10 repeated Monte Carlo simulations with 100 input samples in each simulation. Changing the tolerance limit to estimate $\mu_{\max }$ in the 
iterative update procedure (Eq. 17) to $1 \%$ and $0.1 \%$ did not improve the prediction accuracy for the presented fermentations (data not shown). However, this might be necessary for other applications. In summary, an accurate prediction of the state variables was achieved.

Several reports have implemented soft sensors to monitor LAB fermentations. Acuña et al. [16] and Peter and Röck [15] implemented a model-based monitoring system for LAB fermentations using the base addition and $\mathrm{pH}$ measurements, whereas the second implementation is limited to monitoring the lactic acid concentration. Fayolle et al. [17] and Payot et al. [18] designed a data-based soft sensor using mid-infrared spectroscopy and conductivity, respectively. However, all studies presented deterministic predictions and did not consider the imperfect knowledge of the process by taking uncertainties into account.

Contrary to the earlier published investigations, this study accounted for several sources of uncertainties in the probabilistic monitoring system and assessed the combined effect of system uncertainties on the predictions. The initial conditions, on-line measurements, and biological model parameters were considered as uncertainty sources. The concentrations of the medium components (initial conditions) vary from batch to batch as the medium preparation procedure underlies uncertainties. The biomass concentration depends on the cryo-stock and pre-culture quality. Since the monitoring system relies on the ammonia addition measurement, it is important to incorporate measurement uncertainties, as well. Mears et al. [12] pointed out that an error of $5 \%$ of the carbon evolution rate or oxygen uptake rate, caused by measurement errors in the exhaust gas, led to errors of more than $50 \%$ in the model prediction of the final biomass concentration in a filamentous fungi process at pilot scale. The exact extent of uncertainties of the initial conditions and measurements could not be determined in the present study because statistically relevant data was not available. 
The implemented uncertainties were instead based on expert knowledge. However, the model parameter uncertainties were obtained in the parameter regression step that has been presented above.

The monitoring system predicted the current state variables and forecasted the future course of the fermentation and could therefore support a lean production. If this monitoring system is applied at production sites, it will provide plant operators with a PAT tool to monitor the biological variables in the fermentation process, such as biomass concentration, instead of on-line ammonia addition measurements, where the latter are difficult to comprehend (as shown in the virtual implementation in the Supplementary Movies). In addition, the tool could predict whether and when the target cell yield will be reached. This helps run the batch period optimally and schedule other unit operations: All downstream processing steps could be coordinated with the upstream fermentation batch time and therefore be prepared in time. Moreover, cleaning, sterilization, media preparation, and pre-culture steps affiliated with the start up of the batch process could be optimized to reduce the overall downtime of the fermentation unit. An optimized schedule with efficient utilization of the different operation units can contribute to a more economical operation of the production plant. The monitoring system could also cover the early diagnosis of process failures and warn the operators if biomass growth had stopped unexpectedly. The standstill of ammonia addition is a sign of interrupted biomass growth, as it happened in the shown fermentation after $3 \mathrm{~h}$ (Fig. 5, time $=3 \mathrm{~h}$ ). However, a warning should only be given in case the ammonia addition stopped for a longer period of time - in contrast to the present fermentation, where the ammonia addition stopped only for a short while because the $\mathrm{pH}$ controller overshot. Furthermore, the system could be extended to calculate the risk of not achieving the target biomass yield as a result of the outcome of the soft sensor, which provides the probability distribution of biomass 
concentration at the end of a given batch. It could then be implemented for risk-based monitoring and be further developed for control purposes.

\section{Conclusion}

A probabilistic model-based soft sensor was proposed for the monitoring of $S$. thermophilus fermentations. State variables, such as biomass, substrate, and lactic acid, which were not possible to be measured on-line, could be successfully predicted. The predictions were based on very limited available on-line measurements, namely base addition and $\mathrm{pH}$ measurements since exhaust gas measurements were not available. The aim was achieved by coupling a biokinetic model and a mixed weak acid/base model (for the $\mathrm{pH}$ calculation), which were validated comprehensively. Uncertainties in the initial substrate concentration, base addition, and biological model parameters were quantified and accounted for using Monte Carlo simulations in the probabilistic monitoring system. The future objective of this study will be to implement the monitoring system for on-line risk-based monitoring and control in pilotand large-scale LAB studies.

\section{Competing interest}

The authors declare that they have no competing interests.

\section{Acknowledgement}

This project has received funding from the European Union's Horizon 2020 research and innovation program under the Marie Skłodowska-Curie grant agreement No 643056 (Biorapid project). We are thankful for the cooperation with Chr. Hansen A/S, and the support from Klaus Pellicer Alborch (Technische Universität Berlin) during the experiments. 


\section{Nomenclature}

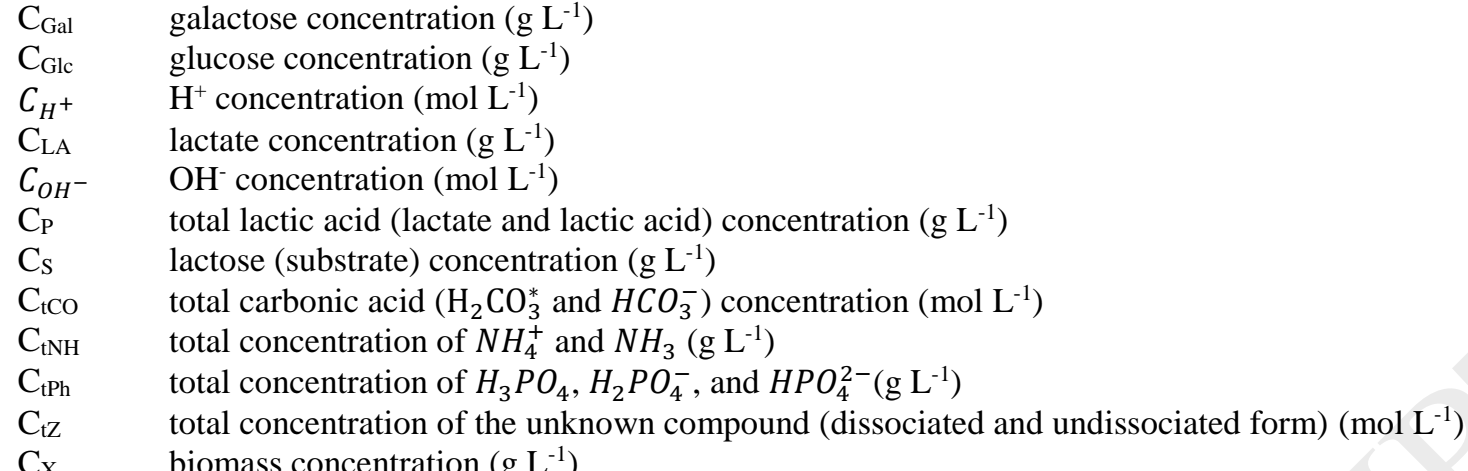

Error $_{i} \quad$ Weighted model prediction error of a component at time point $i$

$\mathrm{f}_{\mathrm{d}} \quad$ divalent activity coefficients (-)

$f_{\text {lag }} \quad$ lag-time function (-)

$\mathrm{f}_{\mathrm{m}} \quad$ monovalent activity coefficients (-)

$\mathrm{f}_{\mathrm{P}} \quad$ lactic acid inhibition function (-)

$\mathrm{f}_{\mathrm{pH}} \quad \mathrm{pH}$ dependency function (-)

$\mathrm{f}_{\mathrm{S}} \quad$ substrate limitation and inhibition function (-)

$\mathrm{H}_{2} \mathrm{CO}_{3}^{*}$ dissolved $\mathrm{CO}_{2}$ and $\mathrm{H}_{2} \mathrm{CO}_{3}$

$\mathrm{I} \quad$ ionic strength $\left(\mathrm{g} \mathrm{L}^{-1}\right)$

$\mathrm{K}_{\mathrm{C} 1}^{\prime} \quad$ apparent equilibrium constant for the carbonic acid system (-)

$\mathrm{K}_{\mathrm{I}} \quad$ substrate inhibition parameter $\left(\mathrm{g} \mathrm{L}^{-1}\right)$

$\mathrm{K}_{\mathrm{La}} \quad$ lactate inhibition parameter $\left(\mathrm{g} \mathrm{L}^{-1}\right)$

$\mathrm{K}_{\mathrm{La} 1} \quad \mathrm{pH}$ dependent lactate inhibition parameter $\left(\mathrm{g} \mathrm{L}^{-1}\right)$

$\mathrm{K}_{\mathrm{LA}}^{\prime} \quad$ apparent equilibrium constant for the lactic acid system (-)

$\mathrm{K}_{\mathrm{NH}}^{\prime} \quad$ apparent equilibrium constant for the ammonia system (-)

$\mathrm{K}_{\mathrm{P}} \quad \mathrm{P}$-controller controller gain

$\mathrm{K}_{\mathrm{P}, \mathrm{La}} \quad$ 2. lactate inhibition parameter $\left(\mathrm{L} \mathrm{g}^{-1}\right)$

$\mathrm{K}_{\mathrm{P}, \mathrm{pH} 1} \quad$ lactate inhibition $\mathrm{pH}$ parameter (-)

$\mathrm{K}_{\mathrm{P}, \mathrm{pH} 2} \quad$ 2. lactate inhibition $\mathrm{pH}$ parameter (-)

$\mathrm{K}_{\mathrm{P} 1}^{\prime} \quad$ apparent equilibrium constant for the phosphoric acid system (-)

$\mathrm{K}_{\mathrm{P} 2}^{\prime} \quad$ apparent equilibrium constant for the dihydrogen phosphate system (-)

$\mathrm{K}_{\mathrm{r}, \mathrm{C} 1}^{\prime} \quad$ apparent reverse rate constant for carbonic acid dissociation $\left(\mathrm{s}^{-1}\right)$

$\mathrm{K}_{\mathrm{r}, \mathrm{LA}}^{\prime} \quad$ apparent reverse rate constant for lactic acid dissociation $\left(\mathrm{s}^{-1}\right)$

$\mathrm{K}_{\mathrm{r}, \mathrm{NH}}^{\prime} \quad$ apparent reverse rate constant for $\mathrm{NH}_{4}$ dissociation $\left(\mathrm{s}^{-1}\right)$

$\mathrm{K}_{\mathrm{r}, \mathrm{P} 1}^{\prime} \quad$ apparent reverse rate constant for $\mathrm{H}_{3} \mathrm{PO}_{4}$ dissociation $\left(\mathrm{s}^{-1}\right)$

$\mathrm{K}_{\mathrm{r}, \mathrm{P} 2}^{\prime} \quad$ apparent reverse rate constant for $\mathrm{H}_{2} \mathrm{PO}_{4}^{-}$dissociation $\left(\mathrm{s}^{-1}\right)$

$\mathrm{K}_{\mathrm{r}, \mathrm{W}}^{\prime} \quad$ apparent reverse rate constant for water dissociation $\left(\mathrm{s}^{-1}\right)$

$\mathrm{K}_{\mathrm{S}} \quad$ substrate limitation parameter $\left(\mathrm{g} \mathrm{L}^{-1}\right)$

$\mathrm{K}_{\mathrm{W}}^{\prime} \quad$ apparent equilibrium constant for the water system (-)

$\mathrm{K}_{\mathrm{Z}}^{\prime} \quad$ apparent equilibrium constant for the unspecified compound system (-)

$\mathrm{n} \quad$ number of measurement points

$\mathrm{pH}_{\mathrm{opt}} \quad$ optimal $\mathrm{pH}$ parameter in the $\mathrm{pH}$ function (-)

$\mathrm{pH}_{\text {opt_lag }}$ optimal $\mathrm{pH}$ for the lag-time fit (-)

$\mathrm{pH}_{\mathrm{set}} \quad \mathrm{pH}$ control set point (-)

$p K_{C 1} \quad \mathrm{pK}_{\mathrm{a}}$ constant for carbonic acid dissociation

$p K_{L A} \quad \mathrm{pK}_{\mathrm{a}}$ constant for lactic acid dissociation

$p K_{N H} \quad \mathrm{pK}_{\mathrm{a}}$ constant for $\mathrm{NH}_{4}$ dissociation

$p K_{P 1} \quad \mathrm{pK}_{\mathrm{a}}$ constant for $\mathrm{H}_{3} \mathrm{PO}_{4}$ dissociation

$p K_{P 2} \quad \mathrm{pK}_{\mathrm{a}}$ constant for $\mathrm{H}_{2} \mathrm{PO}_{4}^{-}$dissociation

$p K_{W} \quad \mathrm{pK}_{\mathrm{a}}$ constant for water dissociation

$p K_{Z} \quad \mathrm{pK}_{\mathrm{a}}$ constant for the unspecified compound dissociation

$\mathrm{q}_{\mathrm{Gal}} \quad$ volumetric galactose secretion rate $\left(\mathrm{C}-\mathrm{mol} \mathrm{L}^{-1} \mathrm{~h}^{-1}\right)$

qNH volumetric ammonia consumption rate $\left(\mathrm{mol} \mathrm{L}^{-1} \mathrm{~h}^{-1}\right)$

$\mathrm{q}_{\mathrm{NH}, \text { add }} \quad$ volumetric ammonia addition rate $\left(\mathrm{mol} \mathrm{L}^{-1} \mathrm{~h}^{-1}\right)$ 
qP volumetric lactic acid secretion rate $\left(\mathrm{C}-\mathrm{mol} \mathrm{L}^{-1} \mathrm{~h}^{-1}\right)$

qPh volumetric phosphoric acid consumption rate $\left(\mathrm{mol} \mathrm{L}^{-1} \mathrm{~h}^{-1}\right)$

qs volumetric substrate consumption rate $\left(\mathrm{C}-\mathrm{mol} \mathrm{L}^{-1} \mathrm{~h}^{-1}\right)$

$\mathrm{q}_{\mathrm{X}} \quad$ volumetric biomass growth rate $\left(\mathrm{C}-\mathrm{mol} \mathrm{L}^{-1} \mathrm{~h}^{-1}\right)$

RE relative error (-)

RMSSE root mean sum of squared errors $\left(\mathrm{g} \mathrm{L}^{-1}\right)$

$\mathrm{T}$ temperature in the bioreactor $(\mathrm{K})$

$\mathrm{t}$ time variable $(\mathrm{h})$

$t_{\text {lag }} \quad$ lag-time coefficient (h)

$\mathrm{w}_{\mathrm{j}} \quad$ maximum value of the state $\mathrm{j}$ for the weighted error in the objective function

$\mathrm{Y}_{\text {gal }} \quad$ galactose yield $\left(\mathrm{g} \mathrm{g}^{-1}\right)$

$\mathrm{Z}_{\mathrm{i}} \quad$ charge number of the $\mathrm{i}$-th ion

$\hat{y}_{i} \quad$ i-th model value of one output $\left(\mathrm{g} \mathrm{L}^{-1}\right)$

$y_{\text {meas }, i} \quad \mathrm{i}$-th measurement value of one output $\left(\mathrm{g} \mathrm{L}^{-1}\right)$

\section{Greek Letters}

$\alpha \quad$ growth related production coefficient of lactic acid $\left(\mathrm{g} \mathrm{g}^{-1}\right)$

$\hat{\theta}_{i} \quad$ estimated parameter value

$\mu_{\max }$ maximum specific growth rate $\left(\mathrm{h}^{-1}\right)$

$\sigma \quad$ standard deviation

$\sigma_{\mathrm{pH}} \quad$ spread parameter is the gaussian $\mathrm{pH}$ function

$\sigma_{\text {lag }}$ standard deviation of the lag-time fit

$\sigma_{\widehat{\theta}_{i}} \quad$ standard deviation of the estimated parameter 


\section{References}

[1] A. Von Wright, L. Axelsson, Lactic Acid Bacteria: An Introduction, in: S. Lahtinen, A.C. Ouwehand, S. Salminen, A. VonWright (Eds.), Lact. Acid Bact. Microbiol. Funct. Asp., 4th ed., CRC Press, Taylor \& Francis, Boca Raton, 2012: pp. 1-16.

[2] S. Patel, A. Majumder, A. Goyal, Potentials of Exopolysaccharides from Lactic Acid Bacteria, Indian J. Microbiol. 52 (2012) 3-12.

[3] B. Sonnleitner, Automated Measurement and Monitoring of Bioprocesses: Key Elements of the M3C Strategy, in: Adv. Biochem. Eng. Biotechnol., 2012: pp. 1-33.

[4] FDA, Guidance for Industry PAT - A Framework for Innovative Pharmaceutical Development, Manufacturing, and Quality Assurance, U.S. Food and Drug Administration, U.S. Department of Health and Human Services, 2004.

[5] R. Luttmann, D.G. Bracewell, G. Cornelissen, K. V. Gernaey, J. Glassey, V.C. Hass, C. Kaiser, C. Preusse, G. Striedner, C.F. Mandenius, Soft sensors in bioprocessing: A status report and recommendations, Biotechnol. J. 7 (2012) 1040-1048.

[6] K. V Gernaey, A.E. Lantz, P. Tufvesson, J.M. Woodley, G. Sin, Application of mechanistic models to fermentation and biocatalysis for next-generation processes., Trends Biotechnol. 28 (2010) 346-54.

[7] L. Mears, S.M. Stocks, M.O. Albaek, G. Sin, K. V. Gernaey, Mechanistic Fermentation Models for Process Design, Monitoring, and Control, Trends Biotechnol. 35 (2017) 914-924.

[8] P. Kadlec, B. Gabrys, S. Strandt, Data-driven Soft Sensors in the process industry, Comput. Chem. Eng. 33 (2009) 795-814.

[9] J. Alves-Rausch, R. Bienert, C. Grimm, D. Bergmaier, Real time in-line monitoring of large scale Bacillus fermentations with near-infrared spectroscopy, J. Biotechnol. 189 (2014) 120-128.

[10] P. Ödman, C.L. Johansen, L. Olsson, K. V. Gernaey, A.E. Lantz, On-line estimation of biomass, glucose and ethanol in Saccharomyces cerevisiae cultivations using in-situ multi-wavelength fluorescence and software sensors, J. Biotechnol. 144 (2009) 102112.

[11] A. Golabgir, C. Herwig, Combining Mechanistic Modeling and Raman Spectroscopy for Real-Time Monitoring of Fed-Batch Penicillin Production, Chemie-IngenieurTechnik. 88 (2016) 764-776.

[12] L. Mears, S.M. Stocks, M.O. Albaek, G. Sin, K. V. Gernaey, Application of a mechanistic model as a tool for on-line monitoring of pilot scale filamentous fungal fermentation processes - The importance of evaporation effects, Biotechnol. Bioeng. 114 (2017) 589-599.

[13] R. Lencastre Fernandes, V.K. Bodla, M. Carlquist, A.-L. Heins, A. Eliasson Lantz, G. Sin, K. V. Gernaey, Applying Mechanistic Models in Bioprocess Development, in: Adv. Biochem. Eng. Biotechnol., 2013: pp. 137-166.

[14] G. Sin, K. V Gernaey, A.E. Lantz, Good modeling practice for PAT applications: propagation of input uncertainty and sensitivity analysis., Biotechnol. Prog. 25 (2009) 1043-1053.

[15] E. Peter, H. Röck, On-line estimation of lactic acid concentration during batch fermentations of Streptococcus thermophilus based on $\mathrm{pH}$ measurement, 12th Int. Conf. Control. Autom. Syst. (2012) 851-855.

[16] G. Acuña, E. Latrille, C. Béal, G. Corrieu, A. Chéruy, On-line estimation of biological variables during $\mathrm{pH}$ controlled lactic acid fermentations, Biotechnol. Bioeng. 44 (1994) 1168-1176.

[17] P. Fayolle, D. Picque, G. Corrieu, Monitoring of fermentation processes producing 
lactic acid bacteria by mid-infrared spectroscopy, Vib. Spectrosc. 14 (1997) 247-252.

[18] T. Payot, M. Fick, G. Chimique, On-line estimation of lactic acid concentration by conductivity measurement in fermentation broth, Biotechnol. Tech. 11 (1997) 17-20.

[19] J. Villadsen, J. Nielsen, G. Lidén, Bioreaction Engineering Principles, Springer US, Boston, MA, 2011.

[20] C. Åkerberg, K. Hofvendahl, B. Hahn-Hägerdal, G. Zacchi, Modelling the influence of $\mathrm{pH}$, temperature, glucose and lactic acid concentrations on the kinetics of lactic acid production by Lactococcus lactis ssp. lactis ATCC 19435 in whole-wheat flour, Appl. Microbiol. Biotechnol. 49 (1998) 682-690.

[21] M. Aghababaie, M. Khanahmadi, M. Beheshti, Developing a detailed kinetic model for the production of yogurt starter bacteria in single strain cultures, Food Bioprod. Process. 94 (2015) 657-667.

[22] A.W. Schepers, J. Thibault, C. Lacroix, Lactobacillus helveticus growth and lactic acid production during $\mathrm{pH}$-controlled batch cultures in whey permeate/yeast extract medium. Part II: kinetic modeling and model validation, Enzyme Microb. Technol. 30 (2002) 187-194.

[23] A. Amrane, Y. Prigent, Influence of an initial addition of lactic acid on growth, acid production and their coupling for batch cultures of Lactobacillus helveticus., Bioprocess Eng. 19 (1998) 307-312.

[24] A.P. Oliveira, J. Nielsen, J. Förster, Modeling Lactococcus lactis using a genome-scale flux model., BMC Microbiol. 5 (2005) 39.

[25] R. Luedeking, E.L. Piret, A Kinetic Study of the Lactic Acid Fermentation. Batch Process at Controlled pH, J. Biochem. Microbiol. Technol. Eng. 1 (1959) 393-412.

[26] R.Y. Peng, T.C.K. Yang, H. Wang, Y. Lin, C. Cheng, Modelling of Lactic Acid Fermentation - An Improvement of Leudeking's Model, J. Chinese Agric. Chem. Soc. 35 (1997) 485-494.

[27] E.V. Musvoto, M.C. Wentzel, R.E. Loewenthal, G.A. Ekama, Integrated ChemicalPhysical Processes Modelling - I. Development of a Kinetic-Based Model for Mixed Weak Acid/Base Systems, Water Res. 34 (2000) 1857-1867.

[28] R.M.C. Dawson, Data for Biochemical Research, Clarendon Press, Oxford, 1969.

[29] R.E. Loewenthal, G.A. Ekama, G.R. Marais, Mixed weak acid/base systems Part I Mixture characterisation., Water SA. 15 (1989) 3-24.

[30] C.W. Davies, Ion Association, Butterworth, Londond, 1962.

[31] G.A.F. Seber, C.J. Wild, Nonlinear Regression, (1989) 792.

[32] G. Sin, K. V. Gernaey, Data Handling and Parameter Estimation, in: M.C.M. van Lossdrecht, P.H. Nielsen, C.M. Lopez-Vazquez, D. Brdjanovic (Eds.), Exp. Methods Wastewater Treat., IWA Publishing Company, 2016: pp. 201-234.

[33] R. Spann, C. Roca, D. Kold, A. Eliasson Lantz, K. V. Gernaey, G. Sin, A Consistent Methodology Based Parameter Estimation for a Lactic Acid Bacteria Fermentation Model, in: A. Espuña, M. Graelss, L. Puigjaner (Eds.), Proc. 27th Eur. Symp. Comput. Aided Process Eng. - ESCAPE 27, Elsevier, 2017: p. 3042.

[34] G. Sin, A.S. Meyer, K. V. Gernaey, Assessing reliability of cellulose hydrolysis models to support biofuel process design-Identifiability and uncertainty analysis, Comput. Chem. Eng. 34 (2010) 1385-1392.

[35] M.D. McKay, R.J. Beckman, W.J. Conover, Comparison of Three Methods for Selecting Values of Input Variables in the Analysis of Output from a Computer Code, Technometrics. 21 (1979) 239-245.

[36] G. Sin, K. V. Gernaey, M.B. Neumann, M.C.M. van Loosdrecht, W. Gujer, Uncertainty analysis in WWTP model applications: A critical discussion using an example from design, Water Res. 43 (2009) 2894-2906. 
[37] R.L. Iman, W.J. Conover, A distribution-free approach to inducing rank correlation among input variables, Commun. Stat. - Simul. Comput. 11 (1982) 311-334.

[38] M.-P.P. Zacharof, R.W. Lovitt, Modelling and simulation of cell growth dynamics, substrate consumption, and lactic acid production kinetics of Lactococcus lactis, Biotechnol. Bioprocess Eng. 18 (2013) 52-64.

[39] H. Ohara, K. Hiyama, T. Yoshida, Kinetic study on $\mathrm{pH}$ dependence of growth and death of Streptococcus faecalis, Appl. Microbiol. Biotechnol. 38 (1992) 403-407.

[40] A.D. Nandasana, S. Kumar, Kinetic modeling of lactic acid production from molasses using Enterococcus faecalis RKY1, Biochem. Eng. J. 38 (2008) 277-284. 


\section{Table Captions}

Table 1. Kinetics for the mixed weak acid/base model. $f_{m}$ and $f_{d}$ are mono- and divalent activity coefficients, respectively.

Table 2. Parameters of the dynamic model of the S. thermophilus fermentations.

Table 3. Estimated model parameters including the relative error and correlation matrix.

Table 4. Fermentation conditions and RMSSE of the biomass prediction for all used data sets: parameter estimation, validation, and the monitoring system.

\section{Figure Captions}

Fig. 1. Block diagram of the probabilistic model-base monitoring system.

Fig. 2. Model predictions for a S. thermophilus lab-scale batch fermentation.

Fig. 3. Growth affecting functions of $\mathrm{pH}$ and lactate inhibition.

Fig. 4. Model prediction for a validation lab-scale batch fermentation.

Fig. 5. Probabilistic monitoring system applied to lab-scale batch data of a $S$. thermophilus fermentation.

Fig. 6. 95\% confidence interval of the RMSSE for the biomass prediction during the probabilistic monitoring of a $S$. thermophilus fermentation. 
Table 1. Kinetics for the mixed weak acid/base model. $\mathrm{f}_{\mathrm{m}}$ and $\mathrm{f}_{\mathrm{d}}$ are mono- and divalent activity coefficients, respectively; see Loewenthal et al. (1989) and Musvoto et al. (2000).

\begin{tabular}{|c|c|c|c|}
\hline \multirow[t]{2}{*}{ Reaction } & \multirow[t]{2}{*}{ reaction rate vector } & \multicolumn{2}{|c|}{ apparent equilibrium constant } \\
\hline & & symbol & value \\
\hline $\mathrm{NH}_{4}^{+} \leftrightarrow \mathrm{NH}_{3}+\mathrm{H}^{+}$ & $\mathrm{K}_{\mathrm{r}, \mathrm{NH}}^{\prime} \cdot \mathrm{K}_{\mathrm{NH}}^{\prime} \cdot\left[N H_{4}^{+}\right]-K_{r, N H}^{\prime} \cdot\left[N H_{3}\right] \cdot\left[H^{+}\right]$ & $\mathrm{K}_{\mathrm{NH}}^{\prime}$ & $10^{-p K_{N H}}$ \\
\hline $\mathrm{H}_{3} \mathrm{PO}_{4} \leftrightarrow \mathrm{H}_{2} \mathrm{PO}_{4}^{-}+\mathrm{H}^{+}$ & $\mathrm{K}_{\mathrm{r}, \mathrm{P} 1}^{\prime} \cdot \mathrm{K}_{\mathrm{P} 1}^{\prime} \cdot\left[\mathrm{H}_{3} P O_{4}\right]-K_{r, P 1}^{\prime} \cdot\left[\mathrm{H}_{2} P O_{4}^{-}\right] \cdot\left[\mathrm{H}^{+}\right]$ & $\mathrm{K}_{\mathrm{P} 1}^{\prime}$ & $10^{-p K_{P 1}} / f_{m}^{2}$ \\
\hline $\mathrm{H}_{2} \mathrm{PO}_{4}^{-} \leftrightarrow \mathrm{HPO}_{4}^{2-}+\mathrm{H}^{+}$ & $\mathrm{K}_{\mathrm{r}, \mathrm{P} 2}^{\prime} \cdot \mathrm{K}_{\mathrm{P} 2}^{\prime} \cdot\left[\mathrm{H}_{2} \mathrm{PO}_{4}^{-}\right]-K_{r, P 2}^{\prime} \cdot\left[\mathrm{HPO}_{4}^{2-}\right] \cdot\left[\mathrm{H}^{+}\right]$ & $\mathrm{K}_{\mathrm{P} 2}^{\prime}$ & $10^{-p K_{P 2}} / f_{d}$ \\
\hline $\mathrm{H}_{2} \mathrm{CO}_{3}^{*} \leftrightarrow \mathrm{HCO}_{3}^{-}+\mathrm{H}^{+}$ & $\mathrm{K}_{\mathrm{r}, \mathrm{C} 1}^{\prime} \cdot \mathrm{K}_{\mathrm{C} 1}^{\prime} \cdot\left[\mathrm{H}_{2} \mathrm{CO}_{3}^{*}\right]-K_{r, C 1}^{\prime} \cdot\left[\mathrm{HCO}_{3}^{-}\right] \cdot\left[\mathrm{H}^{+}\right]$ & $\mathrm{K}_{\mathrm{C} 1}^{\prime}$ & $10^{-p K_{C 1}} / f_{m}^{2}$ \\
\hline $\mathrm{C}_{3} \mathrm{H}_{6} \mathrm{O}_{3} \leftrightarrow \mathrm{C}_{3} \mathrm{H}_{5} \mathrm{O}_{3}^{-}+\mathrm{H}^{+}$ & $\mathrm{K}_{\mathrm{r}, \mathrm{LA}}^{\prime} \cdot \mathrm{K}_{\mathrm{LA}}^{\prime} \cdot\left[C_{3} H_{6} O_{3}\right]-K_{r, L A}^{\prime} \cdot\left[C_{3} H_{5} O_{3}^{-}\right] \cdot\left[H^{+}\right]$ & $\mathrm{K}_{\mathrm{LA}}^{\prime}$ & $10^{-p K_{L A}} / f_{m}^{2}$ \\
\hline $\mathrm{H}_{2} \mathrm{O} \leftrightarrow \mathrm{OH}^{-}+H^{+}$ & $\mathrm{K}_{\mathrm{r}, \mathrm{W}}^{\prime} \cdot \mathrm{K}_{\mathrm{W}}^{\prime}-\mathrm{K}_{r, W}^{\prime} \cdot\left[\mathrm{OH}^{-}\right] \cdot\left[\mathrm{H}^{+}\right]$ & $\mathrm{K}_{\mathrm{W}}^{\prime}$ & $10^{-p K_{W}} / f_{m}^{2}$ \\
\hline$Z H^{+} \leftrightarrow Z+H^{+}$ & $\mathrm{K}_{\mathrm{r}, \mathrm{Z}}^{\prime} \cdot \mathrm{K}_{\mathrm{Z}}^{\prime} \cdot\left[Z H^{+}\right]-K_{r, Z}^{\prime} \cdot[Z] \cdot\left[H^{+}\right]$ & $\mathrm{K}_{\mathrm{Z}}^{\prime}$ & $10^{-p K_{z}} / f_{m}^{2}$ \\
\hline
\end{tabular}


Table 2. Parameters of the dynamic model of the $S$. thermophilus fermentations.

\begin{tabular}{|c|c|c|c|}
\hline Symbol & Value & Reference & Uncertainty classification \\
\hline \multicolumn{4}{|c|}{ Biological model } \\
\hline $\mathrm{K}_{\mathrm{I}}$ & $164 \mathrm{~g} \mathrm{~L}^{-1}$ & [20] & \\
\hline $\mathrm{K}_{\mathrm{La}}$ & $19.80 \mathrm{~g} \mathrm{~L}^{-1}$ & parameter estimation & see Table 3 \\
\hline $\mathrm{K}_{\mathrm{P}, \mathrm{La}}$ & $0.24 \mathrm{~L} \mathrm{~g}^{-1}$ & parameter estimation & see Table 3 \\
\hline $\mathrm{K}_{\mathrm{P}, \mathrm{pH} 1}$ & 20 & expert knowledge & \\
\hline $\mathrm{K}_{\mathrm{P}, \mathrm{pH} 2}$ & 7 & expert knowledge & \\
\hline $\mathrm{Ks}_{\mathrm{s}}$ & $0.79 \mathrm{~g} \mathrm{~L}^{-1}$ & {$[20]$} & \\
\hline $\mathrm{pH}_{\mathrm{opt}}$ & 6.39 & parameter estimation & see Table 3 \\
\hline $\mathrm{t}_{\text {lag }}$ & individual parameter estimation & & \\
\hline$Y_{\text {gal }}$ & $0.69 \mathrm{~g} \mathrm{~g}^{-1}$ & parameter estimation & see Table 3 \\
\hline$\alpha$ & $5.19 \mathrm{~g} \mathrm{~g}^{-1}$ & parameter estimation & see Table 3 \\
\hline$\mu_{\max }$ & $2.06 \mathrm{~h}^{-1}$ & parameter estimation & \\
\hline$\sigma_{\mathrm{pH}}$ & 1.42 & parameter estimation & see Table 3 \\
\hline \multicolumn{4}{|c|}{ Mixed weak acid/base model } \\
\hline $\mathrm{K}_{\mathrm{r}, \mathrm{C} 1}^{\prime}$ & $10^{7} \mathrm{~s}^{-1}$ & [27] & uncertainties in the mixed weak \\
\hline $\mathrm{K}_{\mathrm{r}, \mathrm{LA}}^{\prime}$ & $10^{7} \mathrm{~s}^{-1}$ & [27] & acid/base model are not considered \\
\hline $\mathrm{K}_{\mathrm{r}, \mathrm{NH}}^{\prime}$ & $10^{12} \mathrm{~s}^{-1}$ & [27] & because the $\mathrm{pH}$ is measured and \\
\hline $\mathrm{K}_{\mathrm{r}, \mathrm{P} 1}^{\prime}$ & $10^{8} \mathrm{~s}^{-1}$ & [27] & used as input for the data \\
\hline $\mathrm{K}_{\mathrm{r}, \mathrm{P} 2}^{\prime}$ & $10^{12} \mathrm{~s}^{-1}$ & [27] & reconciliation and parameter update \\
\hline $\mathrm{K}_{\mathrm{r}, \mathrm{W}}^{\prime}$ & $10^{10} \mathrm{~s}^{-1}$ & [27] & module \\
\hline $\mathrm{K}_{\mathrm{r}, \mathrm{Z}}^{\prime}$ & $10^{7} \mathrm{~s}^{-1}$ & [27] & \\
\hline$p K_{C 1}$ & $3404.7 /(T-14.8435+0.03279 \cdot T)$ & [29] & \\
\hline$p K_{L A}$ & 3.86 & [28] & \\
\hline$p K_{N H}$ & $2835.8 /(T-0.6322+0.00123 \cdot T)$ & [29] & \\
\hline$p K_{P 1}$ & $799.3 /(T-4.5535+0.01349 \cdot T)$ & [29] & \\
\hline$p K_{P 2}$ & $1979.5 /(T-5.3541+0.01984 \cdot T)$ & [29] & \\
\hline$p K_{W}$ & 14 & {$[29]$} & \\
\hline$p K_{Z}$ & 9.4 & expert knowledge (ami & o acid mix) \\
\hline $\mathrm{T}$ & $313.16 \mathrm{~K}$ & Measurement & \\
\hline \multicolumn{4}{|c|}{ Initial Conditions } \\
\hline $\mathrm{C}_{\mathrm{Gal}, \mathrm{t}=0}$ & $0.0 \mathrm{~g} \mathrm{~L}^{-1}$ & & \\
\hline $\mathrm{C}_{\mathrm{Glc}, \mathrm{t}=0}$ & $0.0 \mathrm{~g} \mathrm{~L}^{-1}$ & & \\
\hline$C_{H^{+}, t=0}$ & dependent on the $\mathrm{pH}$ and ionic strength & & \\
\hline$C_{O H^{-}, t=0}$ & dependent on the $\mathrm{pH}$ and ionic strength & & \\
\hline $\mathrm{CP}_{\mathrm{P}, \mathrm{t}=0}$ & $0.0 \mathrm{~g} \mathrm{~L}^{-1}$ & & \\
\hline $\mathrm{C}_{\mathrm{S}, \mathrm{t}=0}$ & off-line measurements for the parameter & timation and validation & \\
\hline $\mathrm{C}_{\mathrm{S}, \mathrm{t}=0}$ & $65 \mathrm{~g} \mathrm{~L}^{-1}$ for the monitoring system & & normal distribution $\sigma=2.2 \mathrm{~g} \mathrm{~L}^{-1}$ \\
\hline $\mathrm{C}_{\mathrm{tCO}, \mathrm{t}=0}$ & $1.002 \cdot 10^{-5} \mathrm{~mol} \mathrm{~L}^{-1}$ & & \\
\hline $\mathrm{C}_{\mathrm{tNH}, \mathrm{t}=0}$ & off-line measurements for the parameter & timation and validation & \\
\hline $\mathrm{C}_{\mathrm{tNH}, \mathrm{t}=0}$ & $0.005 \mathrm{~g} \mathrm{~L}^{-1}$ for the monitoring system & & \\
\hline $\mathrm{C}_{\mathrm{tPh}, \mathrm{t}=0}$ & off-line measurements for the parameter & timation and validation & \\
\hline $\mathrm{C}_{\mathrm{tPh}, \mathrm{t}=0}$ & $2 \mathrm{~g} \mathrm{~L}^{-1}$ for the monitoring system & & \\
\hline $\mathrm{C}_{\mathrm{tZ}, \mathrm{t}=0}$ & $2 \mathrm{~mol} \mathrm{~L}^{-1}$ & & \\
\hline $\mathrm{CX}_{\mathrm{X}, \mathrm{t}=0}$ & $0.025 \mathrm{~g} \mathrm{~L}^{-1}$ for the parameter estimation & d validation & \\
\hline $\mathrm{C}_{\mathrm{X}, \mathrm{t}=0}$ & $0.025 \mathrm{~g} \mathrm{~L}^{-1}$ for the monitoring system & & normal distribution $\sigma=0.0008 \mathrm{~g} \mathrm{~L}^{-1}$ \\
\hline
\end{tabular}


Table 3. Estimated model parameters including the relative error and correlation matrix.

\begin{tabular}{|c|c|c|c|c|c|c|c|c|c|c|c|}
\hline \multirow{2}{*}{$\begin{array}{l}\text { kinetic } \\
\text { parameters }\end{array}$} & \multirow{2}{*}{$\begin{array}{l}\text { estimated } \\
\text { parameter value }\end{array}$} & \multirow{2}{*}{$\begin{array}{l}\text { relative } \\
\text { error [\%] }\end{array}$} & \multicolumn{9}{|c|}{ correlation matrix } \\
\hline & & & $\mu_{\max }$ & $\mathrm{K}_{\mathrm{P}}$ & $\mathrm{K}_{\mathrm{La}}$ & $\mathrm{pH}_{\text {opt }}$ & $\sigma_{\mathrm{pH}}$ & $\alpha$ & $\begin{array}{r}\mathrm{pH}_{\mathrm{opt}} \\
-\mathrm{lag} \\
\end{array}$ & $\sigma_{\text {lag }}$ & $Y_{\text {gal }}$ \\
\hline$\mu_{\max }$ & 2.06 & 1 & 1 & -0.74 & -0.83 & -0.17 & 0.5 & -0.08 & -0.52 & 0.53 & 0 \\
\hline $\mathrm{K}_{\mathrm{P}, \mathrm{La}}$ & 0.24 & 13 & & 1 & 0.77 & -0.2 & -0.58 & -0.05 & 0.39 & -0.28 & 0.04 \\
\hline $\mathrm{K}_{\mathrm{La}}$ & 19.80 & 0 & & & 1 & -0.07 & -0.54 & 0.31 & 0.44 & -0.35 & -0.28 \\
\hline $\mathrm{pH}_{\mathrm{opt}}$ & 6.39 & 1 & & & & 1 & -0.52 & -0.13 & 0.76 & -0.86 & 0.02 \\
\hline$\sigma_{\mathrm{pH}}$ & 1.42 & 3 & & & & & 1 & 0.08 & -0.93 & 0.85 & 0.06 \\
\hline$\alpha$ & 5.19 & 0 & & & & & & 1 & -0.1 & 0.12 & -0.4 \\
\hline $\mathrm{pH}_{\text {opt-lag }}$ & 5.70 & 1 & & & & & & & 1 & -0.97 & -0.03 \\
\hline$\sigma_{\text {lag }}$ & 0.3 & 9 & & & & & & & & & 0.03 \\
\hline$Y_{\text {gal }}$ & 0.69 & 5 & & & & & & & & & 1 \\
\hline
\end{tabular}


Table 4. Fermentation conditions and RMSSE of the biomass prediction for all used data sets: parameter estimation, validation, and the monitoring system.

\begin{tabular}{|c|c|c|c|c|}
\hline batch data & $\mathrm{pH}$ & initial lactose conc. $\left[\mathrm{g} \mathrm{L}^{-1}\right]$ & RMSSE $\left[\mathrm{g} \mathrm{L}^{-1}\right]$ & final biomass $\left[\mathrm{g} \mathrm{L}^{-1}\right]^{*}$ \\
\hline \multirow{5}{*}{ 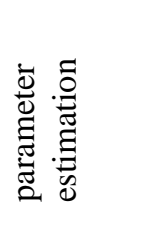 } & 5.5 & 65 & 0.3 & $2.45 \pm 0.1$ \\
\hline & 6 & 65 & 0.2 & $6.0 \pm 0.2$ \\
\hline & 6 & 65 & 0.6 & $6.0 \pm 0.1$ \\
\hline & 6.5 & 65 & 0.3 & $5.7 \pm 0.1$ \\
\hline & 7 & 65 & 0.6 & $2.2 \pm 0.2$ \\
\hline \multirow{2}{*}{ 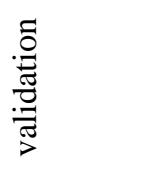 } & 6 & 20 & 0.2 & $2.1 \pm 0.2$ \\
\hline & 6 & 20 & 0.2 & $1.8 \pm 0.1$ \\
\hline \multirow{3}{*}{ 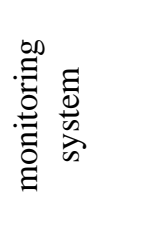 } & $6^{* *}$ & 65 & $0.5 \pm 0.1$ & $5.9 \pm 0.1$ \\
\hline & $6^{* *}$ & 65 & $0.5 \pm 0.1$ & $5.8 \pm 0.2$ \\
\hline & $6^{* *}$ & 65 & $0.5 \pm 0.1$ & $5.9 \pm 0.2$ \\
\hline
\end{tabular}

* with standard deviation of the last measurement at ca. $6 \mathrm{~h}$ fermentation time

** the initial $\mathrm{pH}$ was the $\mathrm{pH}$ of the medium (around $\mathrm{pH}=7$ ). The fermentation was controlled at $\mathrm{pH}=6$. 


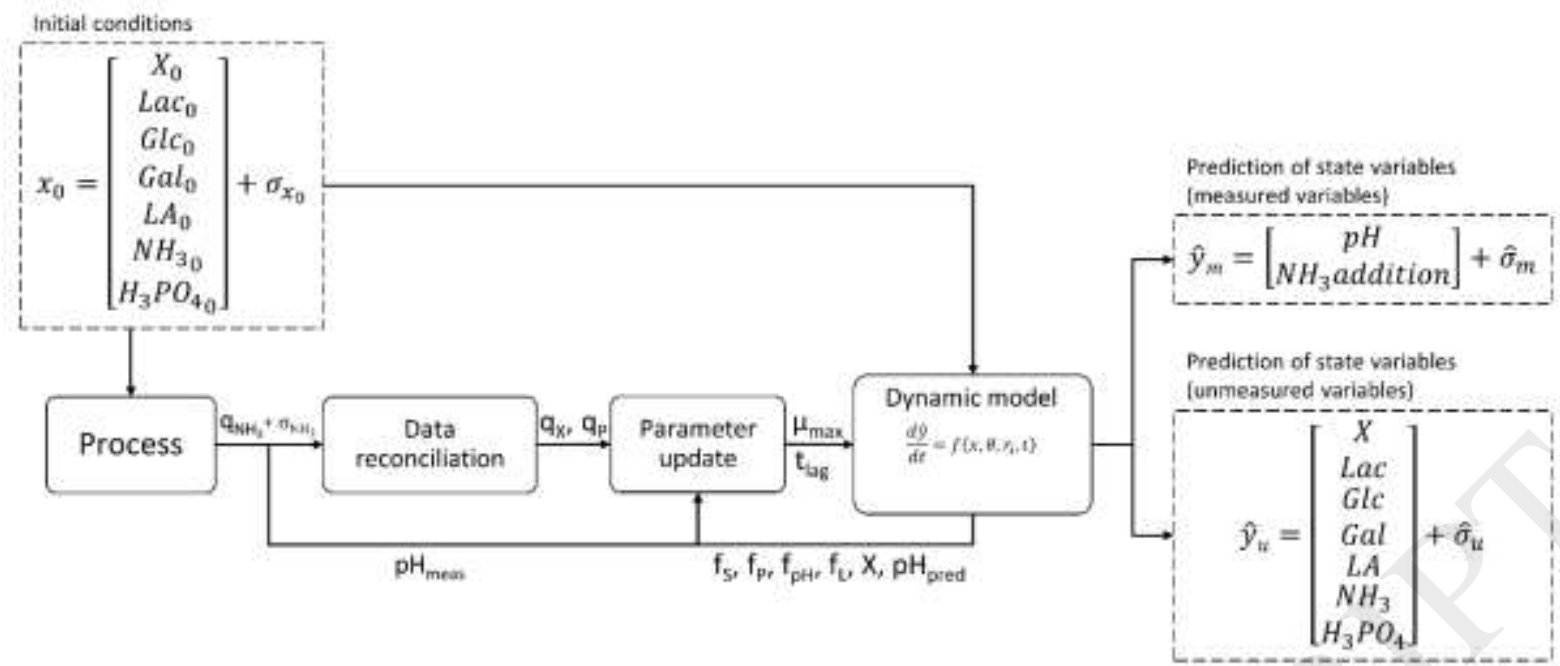

Fig. 1. Block diagram of the probabilistic model-base monitoring system. The initial conditions for the model were defined according to the process specifications including $10 \%$ uncertainties in the lactose and biomass concentration. The on-line measured ammonia addition rate $\mathrm{qNH}_{\mathrm{NH}}$ was used as input for the data reconciliation module to update the biomass growth and lactic acid production rate based on the charge balance and the lactic acid production rate expression. The parameter update module used the updated rates and the $\mathrm{pH}$ as input to update the model parameters $\mu_{\max }$ and $t_{\mathrm{lag}}$ for the dynamic model. Monte Carlo simulations of the dynamic model were performed considering uncertainties in the initial lactose concentration, measured ammonia addition, and model parameters. The output of the dynamic model was a probability distribution of the state variables. 

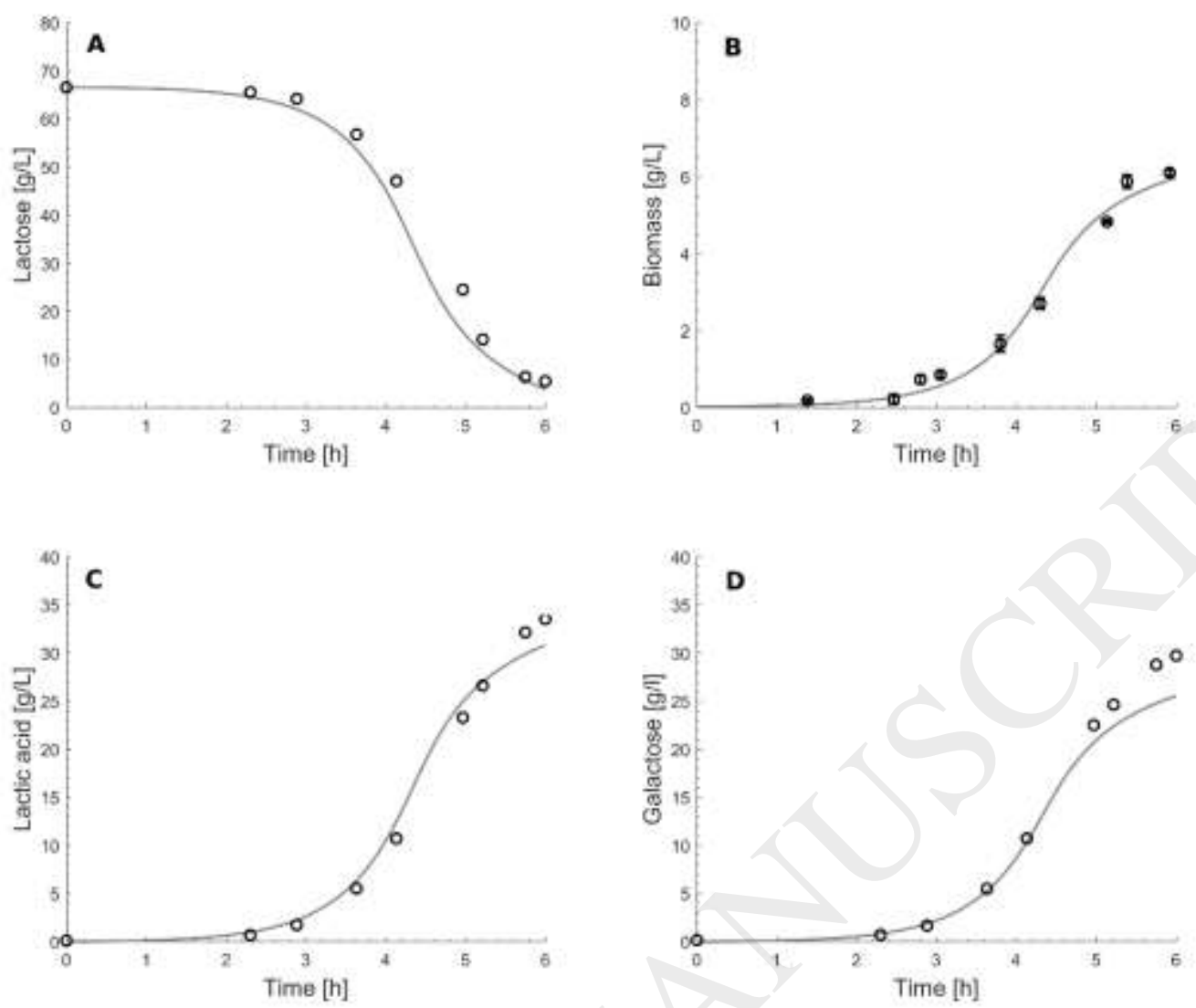

Fig. 2. Model predictions for a S. thermophilus lab-scale batch fermentation. . Lactose (A), biomass with standard deviation (B), lactic acid (C), and galactose (D) concentrations. The fermentation was performed in a $2 \mathrm{~L}$ stirred tank bioreactor at $300 \mathrm{rpm}, 40{ }^{\circ} \mathrm{C}$, and controlled at $\mathrm{pH}=6$. The model prediction (solid line) for the measurements (circles) of one of the five lab-scale batches that were used for the parameter estimation is shown. The biomass measurement is shown with the standard deviation. 

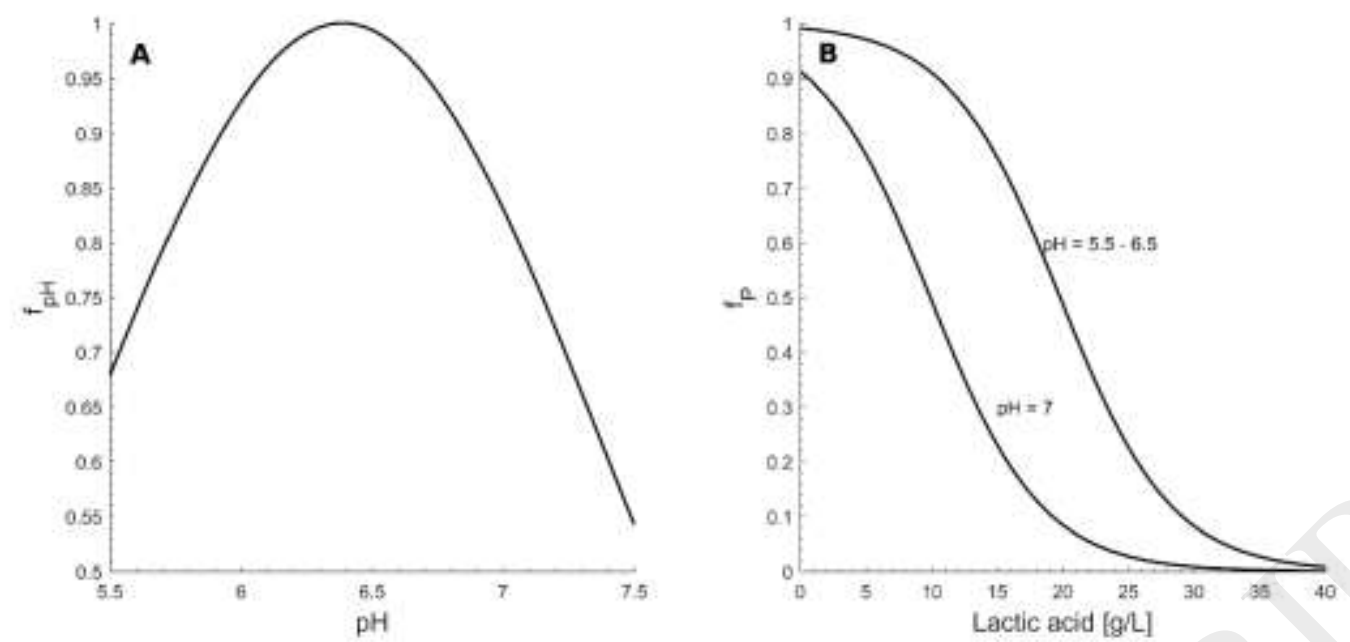

Fig. 3. Growth affecting functions of $\mathrm{pH}$ and lactate inhibition. $\mathrm{pH}$ function vs. $\mathrm{pH}(\mathrm{A})$ and lactate inhibition function vs. lactic acid concentration (B). 

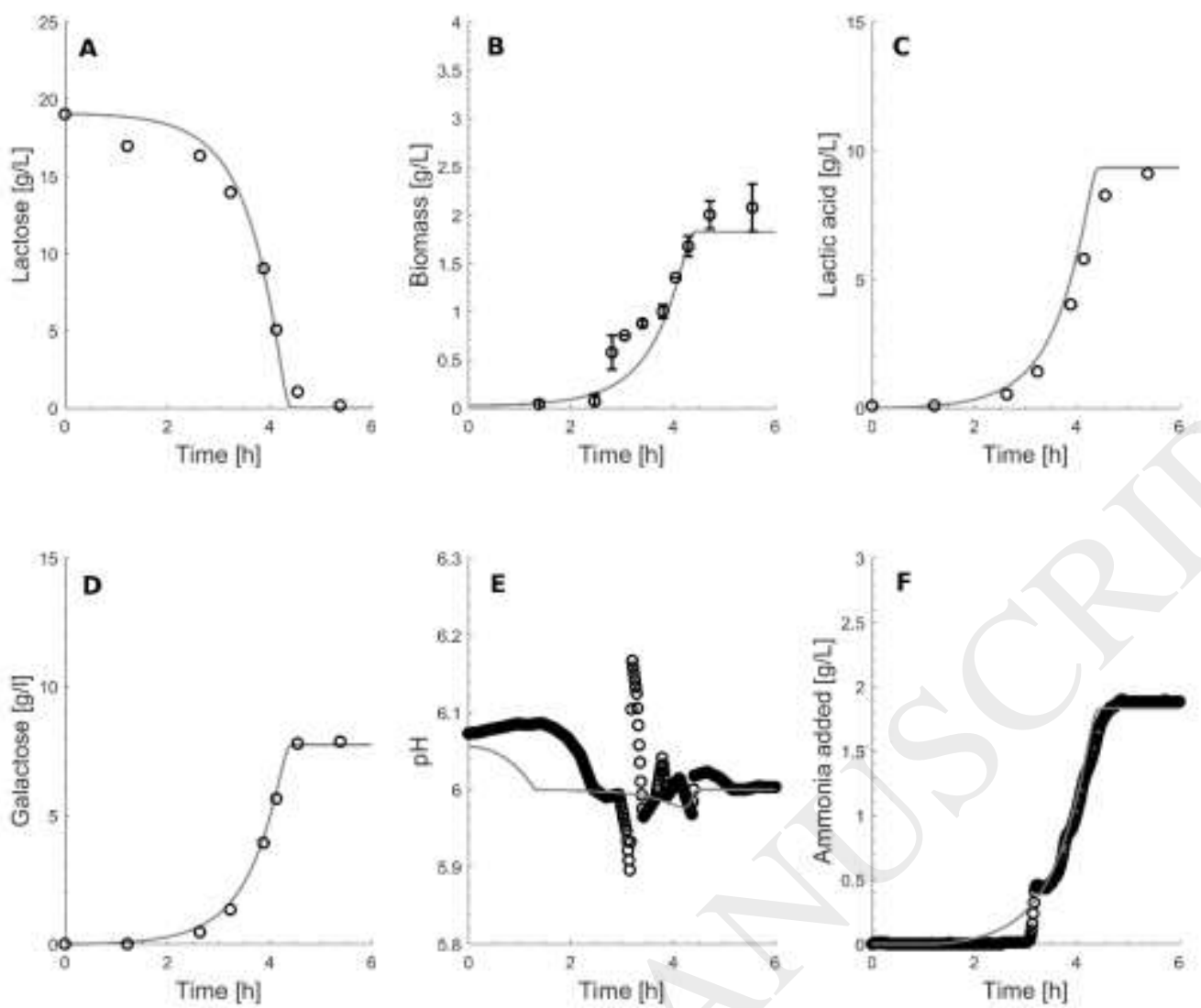

Fig. 4. Model prediction for a validation lab-scale batch fermentation. Lactose (A), biomass with standard deviation (B), lactic acid (C), galactose (D) concentrations, $\mathrm{pH}(\mathrm{E})$, and the added ammonia amount (F). The S. thermophilus fermentation was performed in a $2 \mathrm{~L}$ stirred tank bioreactor at $300 \mathrm{rpm}, 40{ }^{\circ} \mathrm{C}$, and controlled at $\mathrm{pH}=6$. Model prediction (solid line) for the measurements (circles) of one of the two validation lab-scale batches. 

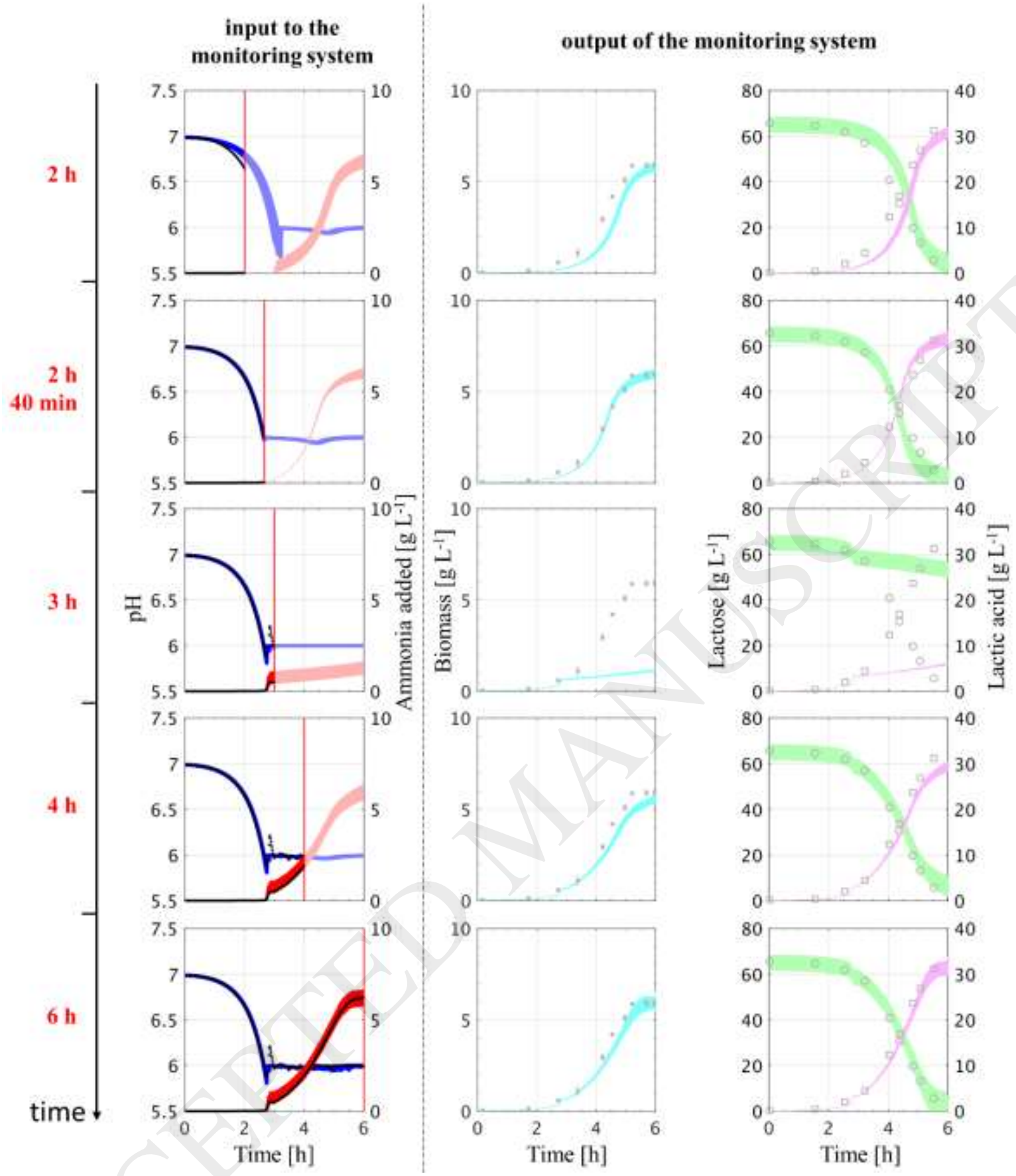

Fig. 5. Probabilistic monitoring system applied to lab-scale batch data of a $S$. thermophilus fermentation. The monitoring system reads in the on-line available data (left column, black dots), ammonia addition and $\mathrm{pH}$, and predicts the state variables every 5 minutes (middle and right column). 100 Monte Carlo simulations of the dynamic model were performed within the monitoring system considering uncertainties in the initial conditions, ammonia addition, and model parameters. The $95 \%$ confidence intervals of the predictions are shown at five time 
points during the fermentation ( $2 \mathrm{~h}, 2 \mathrm{~h} 40 \mathrm{~min}, 3 \mathrm{~h}, 4 \mathrm{~h}, 6 \mathrm{~h}$ ). Predictions of the $\mathrm{pH}$ (blue), ammonia addition (red), biomass (cyan), lactose (green), and lactic acid (magenta) concentrations are shown. The off-line measurements for biomass (gray dot with standard deviation), lactose (gray circle), and lactic acid (gray square) are shown for comparison only, but were not used for the data reconciliation and parameter update (see Fig. 1). 


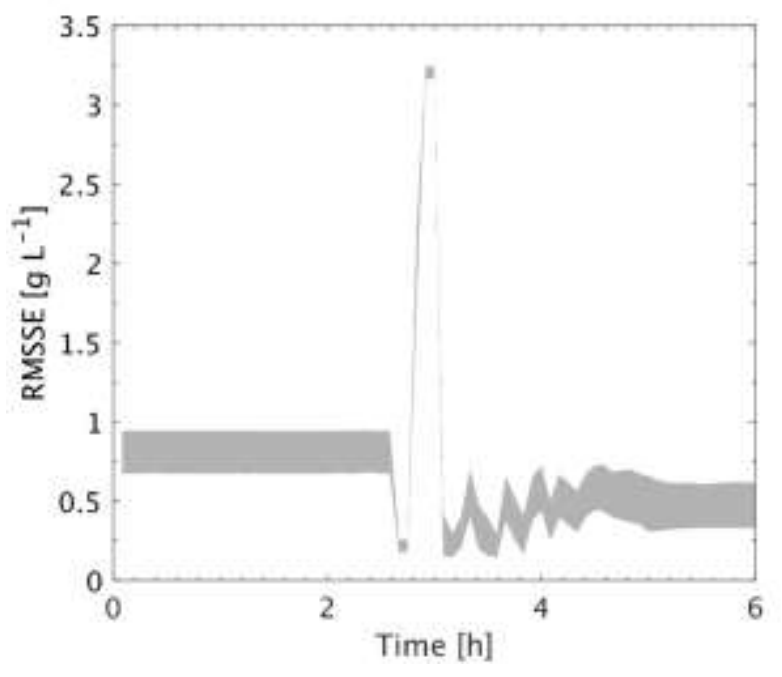

Fig. 6. 95\% confidence interval of the RMSSE for the biomass prediction during the probabilistic monitoring of a S. thermophilus fermentation. 